\title{
Half-century air temperature change above Antarctica: Observed trends and spatial reconstructions
}

\author{
James A. Screen ${ }^{1}$ and Ian Simmonds ${ }^{1}$ \\ Received 2 April 2012; revised 9 July 2012; accepted 10 July 2012; published 25 August 2012.
}

[1] This study provides a comprehensive analysis of observed 50-year (1961-2010) seasonal air temperature trends from radiosonde ascents above Antarctica. Comparisons between multiple radiosonde data sets (homogenized in different ways) at each of eight Antarctic stations reveals substantial differences in the upper-air temperature trend magnitudes and their statistical significance between data sets. However, when considering the average of these data sets at each station, or averaging across all stations, a robust vertical profile of half-century temperature change emerges, characterized by mid-tropospheric warming and stratospheric cooling. Statistically significant Multistation-mean $500 \mathrm{hPa}$ warming $\left(0.1\right.$ to $0.2^{\circ} \mathrm{C}$ decade $\left.^{-1}\right)$ is found in all seasons, whereas the lower stratospheric cooling has been manifest primarily in austral spring and summer, but with larger magnitudes $\left(-1.0\right.$ to $-2.0^{\circ} \mathrm{C}$ decade $\left.^{-1}\right)$. We undertake the first spatial reconstructions of pan-Antarctic upper-air temperature trends. They strongly suggest that both the year-round mid-tropospheric warming and spring and summer lower stratospheric cooling have occurred above the entire continent, although their magnitudes and significance vary regionally. The reconstructed $500 \mathrm{hPa}$ warming trends in winter and spring are largest over West Antarctica, the Ross Ice shelf, Victoria Land and Oates Land, and show close resemblance to those found in previously published surface temperature trend reconstructions, suggesting coupling between the surface and trends aloft.

We speculate that the winter and spring mid-tropospheric warming may, in part, be driven by tropical ocean warming, analogous to proposed mechanisms for the co-located surface warming. The spring and summer lower stratospheric cooling is entirely consistent with the temperature response to ozone depletion.

Citation: Screen, J. A., and I. Simmonds (2012), Half-century air temperature change above Antarctica: Observed trends and spatial reconstructions, J. Geophys. Res., 117, D16108, doi:10.1029/2012JD017885.

\section{Introduction}

[2] 2007-2008 marked the international scientific endeavor of the International Polar Year, and also fifty years since the International Geophysical Year (IGY). A lasting legacy of the IGY is a network of Antarctic research stations that continue to provide valuable scientific data today. These stations now have meteorological records spanning more than half a century, and can potentially tell us a great deal about multidecadal climate change in the Antarctic.

[3] Turner et al. [2005] examined surface temperature trends from these original Antarctic stations, as well as for others that have been established over the intervening years. The spatial pattern of temperature change can be broadly summarized as rapid warming at stations on the Antarctic

\footnotetext{
${ }^{1}$ School of Earth Sciences, University of Melbourne, Melbourne, Victoria, Australia.

Corresponding author: J. A. Screen, School of Earth Sciences, University of Melbourne, Melbourne, Vic 3010, Australia. (screenj@unimelb.edu.au)

C2012. American Geophysical Union. All Rights Reserved. 0148-0227/12/2012JD017885
}

Peninsula and little change, or modest cooling at stations along the coast of East Antarctica. The warming on the eastern side of the Antarctic Peninsula appears to be associated with increasing westerly winds and enhanced warm air advection [Marshall et al., 2006]. Additionally, the westerlies are forced to ascend over the steep orography of the Peninsula and then warm adiabatically as they descend on the lee-side. This warming may have played a role in the collapse of several ice sheets in this region. On the western side of the Antarctic Peninsula the warming appears to be associated with sea ice loss in the surrounding seas and increased ocean-to-atmosphere heat fluxes in the winter [Turner et al., 2005; Turner and Overland, 2009]. Stations around the coast of East Antarctica show more modest and variable surface temperature changes, with most being statistically insignificant [Turner et al., 2005].

[4] Temperature changes over the interior of the continent and along the West Antarctic coast are harder to ascertain due to the sparsity of observations in these regions. A growing number of studies have attempted to reconstruct temperature trends in these data sparse regions [Comiso, 2000; Doran et al., 2002; Chapman and Walsh, 2007; Monaghan et al., 2008; Steig et al., 2009; O'Donnell et al., 
Table 1. Details of the Antarctic Research Stations, Their Data Coverage in the READER Data Set and Their Availability in Various Homogenized Radiosonde Temperature Data Sets

\begin{tabular}{|c|c|c|c|c|c|c|c|c|c|}
\hline Station Name & Record Length & Data Gaps $00 z$ & Data Gaps $12 z$ & Main Obs Time & HadAT2 & RICH-obs & RICH-tau & RAOBCORE & IUK \\
\hline \multicolumn{10}{|c|}{ Core Stations } \\
\hline Amundsen Scott & $1961-2010$ & - & SO $61-10$ & $00 \mathrm{z}$ & - & $\mathrm{Y}$ & $\mathrm{Y}$ & Y & $\mathrm{Y}$ \\
\hline McMurdo & $1956-2010$ & - & SO $56-10$ & $00 \mathrm{z}$ & $\mathrm{Y}$ & $\mathrm{Y}$ & Y & $\mathrm{Y}$ & $\mathrm{Y}$ \\
\hline Casey & $1957-2010$ & - & $\begin{array}{l}\text { SO } 64-77 \\
\text { ID } 78-87\end{array}$ & $00 \mathrm{z}$ & Y & $\mathrm{Y}$ & $\mathrm{Y}$ & Y & $\mathrm{Y}$ \\
\hline Davis & 1959-2010 & - & $\begin{array}{l}\text { ID } 59-70 \\
\text { SO } 71-77 \\
\text { ID } 78-88\end{array}$ & $00 \mathrm{z}$ & - & $\mathrm{Y}$ & $\mathrm{Y}$ & $\mathrm{Y}$ & - \\
\hline Mawson & $1957-2010$ & - & $\begin{array}{l}\text { ID } 57-70 \\
\text { SO } 71-78\end{array}$ & $00 \mathrm{z}$ & $\mathrm{Y}$ & - & - & - & $\mathrm{Y}$ \\
\hline Mirny & $1956-2010$ & - & QT $83-10$ & $00 \mathrm{z}$ & - & $\mathrm{Y}$ & $\mathrm{Y}$ & Y & - \\
\hline Novolazarevskaya & $1961-2010$ & - & QT $61-10$ & $00 \mathrm{z}$ & $\mathrm{Y}$ & - & - & - & $\mathrm{Y}$ \\
\hline Halley & $1957-2010$ & ID $57-10$ & - & $12 z$ & Y & $\mathrm{Y}$ & $\mathrm{Y}$ & $\mathrm{Y}$ & $\mathrm{Y}$ \\
\hline \multicolumn{10}{|c|}{ Category 1 Stations } \\
\hline Vostok & $1958-1992$ & - & $\begin{array}{l}\text { ID 58-65 } \\
\text { QT 66-92 }\end{array}$ & $00 z$ & - & - & - & - & - \\
\hline Concordia & $2006-2010$ & ID $06-10$ & - & $12 z$ & - & - & - & - & - \\
\hline Bellingshausen & 1969-1998 & - & ID $69-98$ & $00 \mathrm{z}$ & - & - & - & - & - \\
\hline Faraday & 1954-1982 & ID $54-82$ & - & $12 z$ & - & - & - & - & - \\
\hline Rothera & $2002-2010$ & ID $02-10$ & - & $12 z$ & - & - & - & - & - \\
\hline Marambio & 1983-2010 & ID $83-10$ & - & $12 z$ & - & - & - & - & Y \\
\hline Syowa & $1968-2010$ & - & - & $00 \mathrm{z}$ & $\mathrm{Y}$ & $\mathrm{Y}$ & $\mathrm{Y}$ & Y & $\mathrm{Y}$ \\
\hline Molodeznaja & 1964-1998 & - & - & $00 \mathrm{z}$ & - & - & - & - & - \\
\hline \multicolumn{10}{|c|}{ Category 2 Stations } \\
\hline Dumont d'Urville & $1958-2010$ & ID 59-74 & ID $63-10$ & $00 \mathrm{z}$ & - & $\mathrm{Y}$ & $\mathrm{Y}$ & $\mathrm{Y}$ & $\mathrm{Y}$ \\
\hline Leningradskaya & 1983-1991 & - & ID 83-91 & $00 \mathrm{z}$ & - & - & - & - & - \\
\hline Neumayer & $1983-2010$ & ID $83-10$ & - & $12 z$ & - & - & - & - & - \\
\hline Mario Zuchelli & $1987-2010$ & SO $87-10$ & SO $87-10$ & - & - & - & - & - & - \\
\hline Sanae & 1957-1992 & ID $60-73$ & ID $60-84$ & $00 \mathrm{z}$ & $\mathrm{Y}$ & - & - & - & - \\
\hline
\end{tabular}

${ }^{a}$ Abbreviations used: SO, summer observations only; QT, quarterly observations; ID, insufficient data; Y, data available.

2011; Muto et al., 2011]. These reconstructions are not entirely consistent, probably because of the different statistical techniques employed. They disagree as to whether there has been predominantly warming or cooling in East Antarctica. The Steig et al. [2009] reconstructions stand out as showing the largest and most spatially coherent annual-mean warming in East Antarctica; however, the reality of this interior warming has recently been questioned [O'Donnell et al., 2011]. The other reconstructions depict a more variable pattern of regional annual-mean temperature change in East Antarctica. The various reconstructions also differ with regards to the rate of warming in West Antarctica and on the Peninsula, on what proportion of West Antarctica has warmed significantly, and the seasonality of the temperature changes. However, all these reconstructions agree in three aspects. First, that surface temperature trends over East Antarctica are smaller than those over West Antarctica. Second, that the Peninsula has warmed more rapidly than any other part of the continent and third, that the warming observed on the Antarctic Peninsula extends to much of West Antarctica. This West Antarctic warming has been attributed in part to warming in the tropical Pacific Ocean and associated teleconnections [Ding et al., 2011; Schneider et al., 2012].

[5] All the aforementioned studies have focused on surface temperature changes. A limited number of studies have examined temperature changes in the troposphere. Turner et al. [2006] documented a significant warming of the winter troposphere over the period 1971-2003, based on radiosonde data at nine Antarctic research stations. They found the warming was largest in the mid-to-lower troposphere $(400-700 \mathrm{hPa})$ in winter. It is unclear from this study what the vertical profile of temperature change looks like in the other seasons. An earlier study using only four stations found statistically significant annual-mean warming trends at 500 and $850 \mathrm{hPa}$ over the period 1960-1999 [Marshall, 2002]. Neff et al. [2008] examined trends in $500 \mathrm{hPa}$ geopotential height (related to tropospheric temperature) from radiosonde ascents over the period 1957-2007. They found $500 \mathrm{hPa}$ height increases (indicative of warming) in most months at Amundsen Scott, Halley and McMurdo, but height decreases (indicative of cooling) in the summer months along sections of the East Antarctic coast. Since 1979, upper-air temperatures have been monitored by the satellite Microwave Sounder Unit (MSU). Johanson and Fu [2007] showed Antarctic tropospheric warming in winter and spring, and cooling in summer and autumn, in the MSU data from 1979 to 2005.

[6] Temperature trends in the polar stratosphere have received a lot of attention following the discovery of the Antarctic ozone hole. Radiosonde, satellite and lidar data suggest that the Antarctic stratosphere has significantly cooled in the last 30-50 years [e.g., Randel and Wu, 1999; Ramaswamy et al., 2001; Johanson and Fu, 2007; Randel et al., 2009]. This cooling has been manifest most strongly in austral spring and summer, in association with photochemical ozone loss [see, e.g., Randel et al., 2009, and references therein]. In the lower stratosphere, cooling trends appear to be primarily driven by ozone depletion, whereas in the upper stratosphere they are the consequence of both 


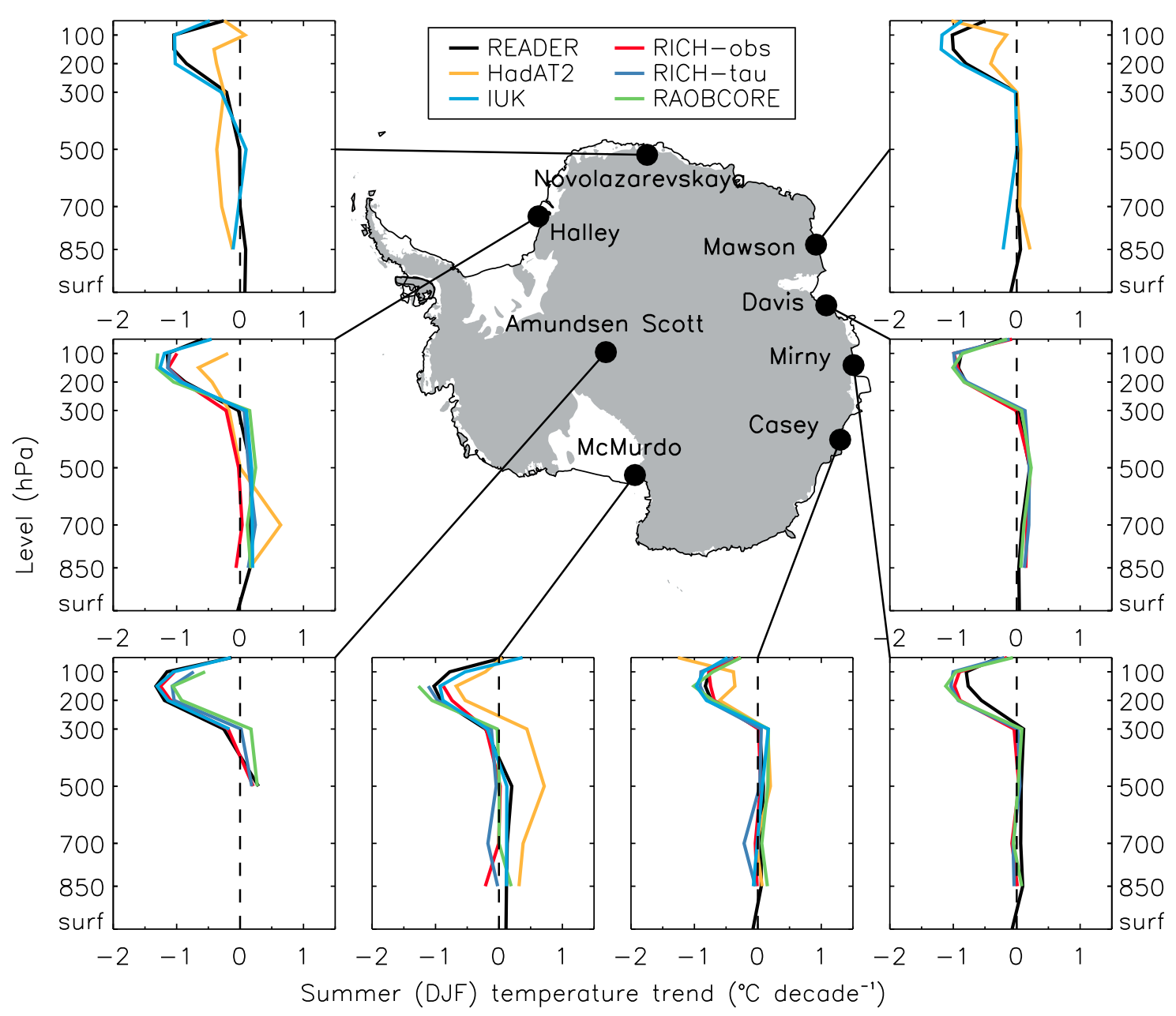

Figure 1. Vertical profile of summer (December-February) air temperature trends, 1961-2010, at eight Antarctic stations. Trends from multiple data sets are shown by the different colors.

ozone changes and increasing greenhouse gas concentrations [Shine et al., 2003].

[7] This study is organized as follows. In section 2, we consider Antarctic temperature trends from the surface to the lower stratosphere from observations at manned Antarctic stations. Our analyses cover a substantially longer period than most previous studies, all seasons, and by considering all atmospheric levels together we can explicitly examine the vertical profile of multidecadal temperature change. We also quantitatively assess uncertainties in Antarctic radiosonde temperature trends by comparative analyses of multiple homogenized data sets. In section 3, we develop and present the first spatial reconstructions of pan-Antarctic temperature trends in the mid-troposphere and lower stratosphere. Taken together, these analyses constitute a comprehensive assessment of multidecadal upper-air temperature trends in the Antarctic.

\section{Observational Analysis}

\subsection{Data and Methods}

[8] We analyze surface and upper-air temperatures from manned Antarctic research stations. Our primary data source are monthly mean air temperatures that have been collated, processed and quality-controlled under the auspices of the
Reference Antarctic Data for Environmental Research (READER) project of the Scientific Committee on Antarctic Research (section 2.1.1). We also utilize several homogenized radiosonde temperature data sets (section 2.1.2). Methods pertaining to the observational analysis are provided in section 2.1.3, whereas those pertaining to our spatial reconstructions of upper-air temperature change are given in section 3.1.

\subsubsection{READER Data}

[9] The READER data set comprises surface and upperair temperature observations from twenty-one Antarctic research stations (Table 1). These in situ data provide the longest possible record of past temperature evolution in the Antarctic [Turner et al., 2004, 2005]. Eight of the twentyone stations have near-continuous records from the late 1950 s or early $1960 \mathrm{~s}$. We refer to these as the core stations (Table 1) and they are the U.S. Amundsen Scott and McMurdo bases; Australian stations Casey, Davis and Mawson; Russian facilities Mirny and Novolazarevskaya; and the UK site Halley. With the exception of Amundsen Scott at the geographic South Pole, all the stations are located around the coast of East Antarctica (Figure 1). All are sited close to sea level, except for Amundsen Scott at an altitude of $2835 \mathrm{~m}$. No permanent research stations are located in West Antarctica, and no continuous upper-air 
records are available for the Antarctic Peninsula or East Antarctic plateau. Nonetheless, the eight core stations provide good longitudinal coverage around East Antarctica and Amundsen Scott provides insight into changes in the interior. Based on data availability at these stations, we consider the 50-year period from 1961 to 2010 .

[10] A further eight of the twenty-one stations have shorter records individually, but are located in proximity to another station, or stations, with overlapping and abutting records. These stations are referred to as Category 1 stations (Table 1) and are used in combination to produce merged time series for the Antarctic Peninsula, central East Antarctica and Enderby Land. These merged records are introduced in section 3.1.1. The remaining five stations have short records and/or large data gaps (Table 1; Category 2 stations) and therefore, they are not used in this study.

[11] We examine temperature trends at each station as a function of season and height. To do this, first we downloaded monthly mean surface and upper-air temperatures $(850,700,500,300,200,150,100,50$ and $30 \mathrm{hPa})$ for two observation times $(12 \mathrm{z}$ and $00 \mathrm{z})$ from the READER website (http://www.antarctica.ac.uk/met/READER/). The surface data come from ground-based instruments whereas the upper-air data are from radiosondes. These monthly means have been derived from daily data. Months with less than $90 \%(30 \%)$ of surface (upper-air) daily observations are flagged and are treated as missing data. Next, the monthly mean air temperatures were converted to anomalies. To avoid spurious anomalies due to insufficient data, a threshold of $50 \%$ ( 25 years) of observations was set. Where this threshold was not met, the data were considered missing over all years for that specific month, level, station and observation time. The anomalies for $00 \mathrm{z}$ and $12 \mathrm{z}$ were then averaged to give monthly means of daily anomalies, and finally these were converted to seasonal-mean anomalies for austral summer (December-February; DJF), autumn (March-May; MAM), winter (July-August; JJA) and spring (SeptemberNovember; SON). Note, it was essential to convert the temperature values into anomalies prior to averaging because the missing data cannot be assumed to occur evenly among months and observation times. Simply averaging the available raw temperature values may have resulted in biased means. We note that none of the stations had near-complete records for both observation times. Each station had a nearcomplete record at one observation time and a patchy (often summer-only) record at the other observation time. The main observation time differs between stations (see Table 1). The resultant trends were largely insensitive to whether daily means were defined from data at $00 \mathrm{z}, 12 \mathrm{z}$ or both (where available). In the main material we only present the latter; however, we also present results for $00 \mathrm{z}$ and $12 \mathrm{z}$ separately in the auxiliary material. ${ }^{1}$

\subsubsection{Homogenized Radiosonde Data}

[12] While the READER data set has undergone intensive quality-control to alleviate spurious data due to, for example, changes in units or transcription and transmission errors [Turner et al., 2004], no efforts have been made to account for changes in radiosonde type or observing practice over time. Such changes can led to discontinuities in radiosonde

\footnotetext{
${ }^{1}$ Auxiliary materials are available in the html. doi:10.1029/ 2012JD017885.
}

temperature records and induce artificial trends [see, e.g., Thorne et al., 2011]. This ongoing issue has led to several projects that have reprocessed the global radiosonde records and attempted to remove temporal inconsistencies through a set of statistical approaches collectively referred to as "homogenization" [Thorne et al., 2005; Haimberger, 2007; Sherwood, 2007; Sherwood et al., 2008; Titchner et al., 2009; Thorne et al., 2011; Haimberger et al., 2012].

[13] In this study we utilize five different homogenized radiosonde sets: the UK Hadley Centre Atmospheric Temperature analysis version 2 (HadAT2) [Thorne et al., 2005], two versions of the Radiosonde Innovation Composite Homogenization (termed RICH-obs and RICH-tau) [Haimberger, 2007; Haimberger et al., 2008, 2012], the Radiosonde Observation Correction using Reanalyses (RAOBCORE) [Haimberger, 2007; Haimberger et al., 2008, 2012], and the Iterative Universal Kriging radiosonde analysis (IUK) [Sherwood, 2007; Sherwood et al., 2008]. While based on largely the same raw data, each data set differs in its statistical approach to homogenization and therefore, has different underlying assumptions. For practical reasons, a complete description of the various homogenization procedures cannot be provided here (for further details the reader is directed to the references above). In short, homogenization procedures generally have two stages. First, shifts or "breakpoints" are detected in the radiosonde observation time series. Once a breakpoint is identified, an adjustment (calculated against a chosen reference data set) can be applied to maintain the temporal consistency of the time series. Both stages of this process involve a number of assumptions and a priori choices. Often statistical relationships between observations at one station and those at surrounding neighbor stations or in atmospheric reanalysis forecast fields (or both) are used to identify breakpoints and/or calculate the adjustments.

[14] In the absence of continuous independent observations for validation it is unclear which homogenization approach is superior. Accordingly, we treat all homogenization approaches as equally credible and examine the temperature trends in all five data sets. By examining trends from multiple homogenized data sets based on different methods and assumptions, and the unhomogenized READER data, we quantitatively assess observational uncertainty in Antarctic upper-air temperature trends.

[15] HadAT2 and IUK were obtained as homogenized monthly mean station time series. RICH and ROABCORE were obtained as homogenized monthly mean gridded products. Since there was never more than one station per gridbox in the Antarctic domain, individual station time series were easily extracted by sub-sampling the grid-boxes containing the Antarctic stations. None of the homogenized products had data for all eight stations (Table 1). We calculated temperature anomalies and seasonal means thereof in precisely the same manner as described above for the READER data. HadAT2, RICH and RAOBCORE were available for the full period 1961-2010. IUK has not been extended beyond 2005 so anomalies and trends derived from it are based on the period 1961-2005.

\subsubsection{Trends and Significance}

[16] Seasonal trends were calculated using least squares linear regression. A few levels at some stations have so few observations that no seasonal anomalies passed the quality- 
control checks and thus, no trends have been calculated. There is no data from 700 and $850 \mathrm{hPa}$ at Amundsen Scott as the monthly mean surface pressure is always below $700 \mathrm{hPa}$ there. The seasonal trends were tested for statistical significance, using a procedure that accounts for temporal autocorrelation. We calculated an effective sample size following Bretherton et al. [1999] and used this value to index a twotailed Student's t-test. We tested for significance at the $95 \%$ $(\mathrm{p}<0.05)$ level.

\subsection{Observed Trends}

[17] Figures 1 to 4 show the vertical profile of temperature trends (1961-2010) at each station for austral summer, autumn, winter and spring, respectively. In each figure, trends are presented from READER and from all five homogenized radiosonde products. At some stations and levels, trends are not shown for all, or in a few cases, any data sets, either because data were not available or because there were insufficient data to pass the quality-control checks. For completeness the READER surface trends are plotted in Figures 1 to 4; however, our focus is trends from the lower troposphere $(850 \mathrm{hPa})$ to the lower stratosphere $(50 \mathrm{hPa})$. Figure 5 shows the number of data sets that depict statistically significant trends in each season, and at each level and station. In the following sections we first examine the austral seasons and stations individually (sections 2.2.1 to 2.2.4) and then multistation means (section 2.2.5). A summary is provided in section 2.3 .

\subsubsection{Summer}

[18] The dominant feature of the summer trends is cooling in the lower stratosphere (Figure 1). The cooling is strongest between 100 and $200 \mathrm{hPa}$ and exceeds $-1.0^{\circ} \mathrm{C}$ decade $^{-1}$ at many stations and in many data sets. The strongest cooling trends are observed at Amundsen Scott and Halley. There is strong agreement between the different data sets in the lower stratosphere, although HadAT2 has a tendency to show weaker cooling trends than other data sets. The summertime 150 and $200 \mathrm{hPa}$ cooling trends are highly robust, being statistically significant at all stations and in all data sets (Figure 5). All stations and the majority of data sets also show significant cooling at $100 \mathrm{hPa}$.

[19] Summer temperature trends in the mid- to lower-troposphere are considerably smaller than in the lower stratosphere, and are more variable by location and data set (Figure 1). At Novolazarevskaya, HadAT2 shows significant cooling at 500 and $700 \mathrm{hPa}$, but this is not corroborated by the other two available data sets (Figure 5). At Halley, there are significant warming trends between 500 and $850 \mathrm{hPa}$ in some, but not all, data sets. All data sets depict $500 \mathrm{hPa}$ warming at Amundsen Scott, with three of four data sets showing statistically significant warming trends. At McMurdo, HadAT2 displays significant warming between 500 and $850 \mathrm{hPa}$, but again this is not corroborated by the other data sets. In fact at $850 \mathrm{hPa}$ there is significant disagreement, with RICH-obs depicting significant cooling. There are very few significant trends of either sign in any of the data sets for the stations located in the Indian Ocean sector (Casey, Mirny, Davis and Mawson).

[20] Summer temperature trends for $00 \mathrm{z}$ and $12 \mathrm{z}$ individually (from READER data only) are largely comparable to those calculated from daily means (auxiliary material Figure S1). The notable exception being that Mawson and Davis show stronger lower stratospheric cooling (by approximately $0.5^{\circ} \mathrm{C}$ decade $^{-1}$ ) at $12 \mathrm{z}$ than at $00 \mathrm{z}$ or in the daily mean. The opposite is true at Mirny but the differences are smaller. However, it is worth noting that $12 \mathrm{z}$ is not the main observation time at any of these stations (Table 1) and although sufficient observations existed ( $25+$ years) to pass the qualitycontrol checks, most of the $12 \mathrm{z}$ observations are from the late 1980s onwards at Davis, from the late 1970s onwards at Mawson, and prior to the early 1980s at Mirny. Thus, the trend differences between $12 \mathrm{z}$ and $00 \mathrm{z}$ may, in part, relate to missing $12 z$ data over parts of the records, rather than real trend differences between these two observation times. It is important to note that the trends based on daily means very closely resemble the trends from $00 \mathrm{z}$ at these stations (auxiliary material Figure S1) and hence, that inclusion of the lesscomplete $12 \mathrm{z}$ data records into the daily means does not result in biased trends based on these daily means.

\subsubsection{Autumn}

[21] The autumn trends show less variation with height than the summer trends, but vary considerably with location and between the data sets (Figure 2). HadAT2 is often an outlier among the different data sets, especially in the lower stratosphere. HadAT2 depicts significant lower stratospheric warming at Novolazarevskaya, Halley, McMurdo, Casey and Mawson. At all these stations other data sets show cooling and at four of these there is significant disagreement, in the sense that at least one of the cooling trends is also statistically significant (Figure 5). If we discount HadAT2, there is a general pattern of weak lower stratospheric cooling at all stations except for Amundsen Scott, where there is no agreement of the sign of the trend.

[22] There is greater consistency between data sets in the troposphere than in the stratosphere, apart from at McMurdo where there is still significant disagreement in the sign of the trends (Figure 2). Mid- to lower-troposphere warming trends are found in all or the majority of data sets at most stations. Statistically significant warming trends are found in some, but not all, data sets at Halley $(500,700 \mathrm{hPa})$, Amundsen Scott (500 hPa), Casey $(500,700,850 \mathrm{hPa})$, Davis (700 hPa) and Mawson (500 hPa) (Figure 5). Of these, Amundsen Scott displays the strongest warming of, on average, $0.3^{\circ} \mathrm{C}$ decade $^{-1}$ at $500 \mathrm{hPa}$. HadAT2 shows significant cooling at 500 and $850 \mathrm{hPa}$ at Novolazarevskaya, but this is not supported by either READER or IUK. No significant autumn tropospheric trends are found in any data set at Mirny.

[23] Autumn temperature trends calculated separately for $00 \mathrm{z}$ and $12 \mathrm{z}$ show differences at certain vertical levels (auxiliary material Figure S2), but these differences are smaller (or at least, no larger) than those already discussed between different data sets. Only three stations (Casey, Mawson and Mirny) have sufficient data from both observation times to calculate trends in both, and we reiterate that the $12 \mathrm{z}$ records at these stations have more missing data than the corresponding $00 \mathrm{z}$ records. Hence, we have more confidence in the trends derived from the latter.

\subsubsection{Winter}

[24] The wintertime stratospheric trends vary considerably between the data sets and with location (Figure 3). There is significant disagreement as to the sign of lower stratospheric trends at Novolazarevskaya and Halley. Again, HadAT2 is an outlier displaying significant warming at these stations in contrast to significant cooling in other data sets. This is not 


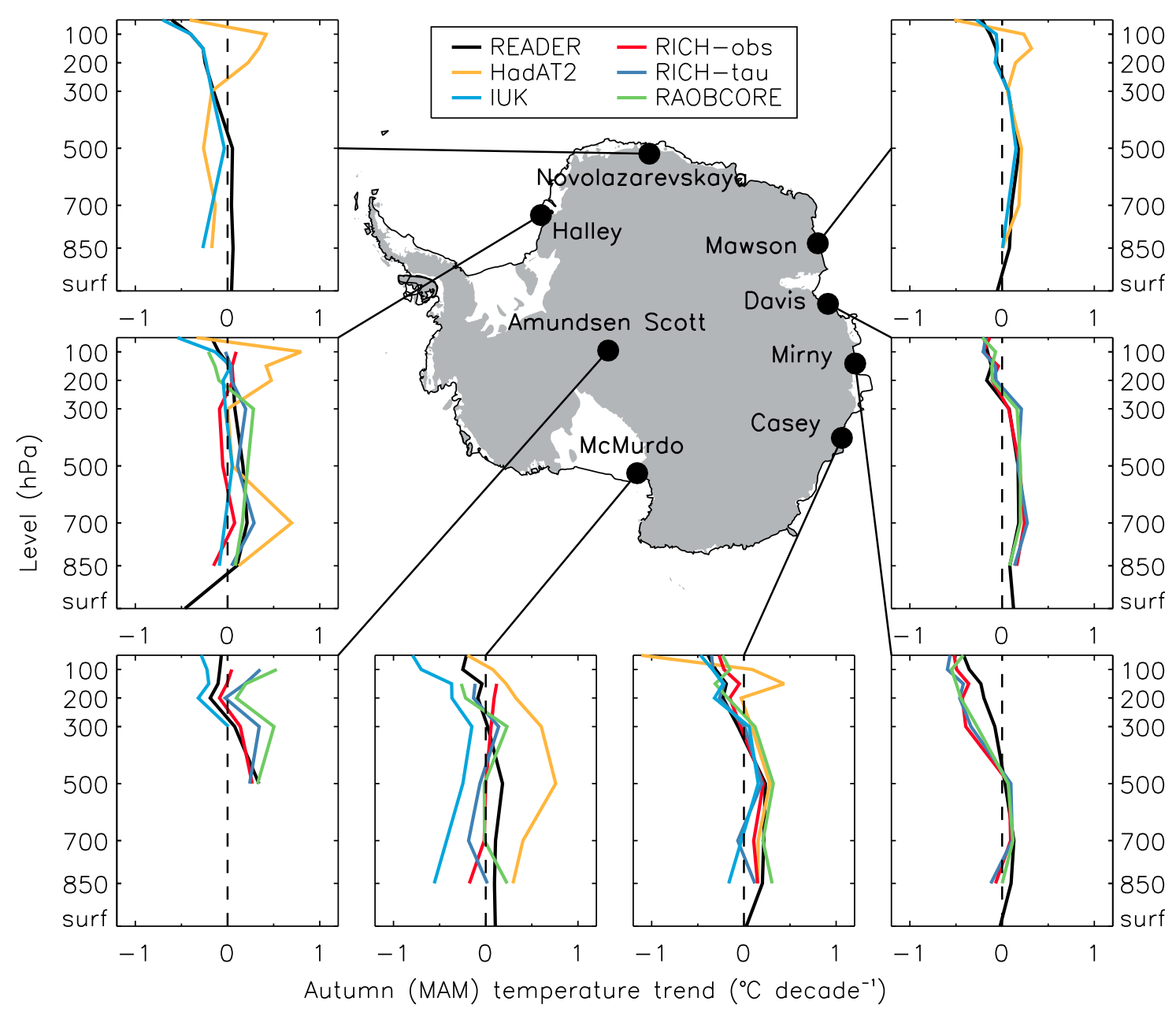

Figure 2. Same as Figure 1, but for autumn (March-May) air temperature trends.

the first study to show large differences between temperature trends derived from various radiosonde products, but HadAT2 is not always the outlier. In fact for other geographical regions, HadAT2 is often closer to the unadjusted data than are alternative homogenized products [Haimberger et al., 2008]. There is consistently significant $100 \mathrm{hPa}$ cooling at Davis, predominantly stratospheric cooling trends at McMurdo, Casey and Mirny (some of which are significant) and consensus on warming trends at $100 \mathrm{hPa}$ and below at Amundsen (some of which are significant) (Figure 5).

[25] The winter tropospheric trends are strongly characterized by warming (Figure 3). Significant tropospheric warming is found in at least one data set at all stations except Davis and Mirny (Figure 5). Further, significant tropospheric warming is found in three or more data sets at Halley, Casey and McMurdo (500 hPa only). Indeed, the $500 \mathrm{hPa}$ warming at Casey is significant in all six data sets, and the 700 and $850 \mathrm{hPa}$ warming at Halley is significant in five of six data sets. At $500 \mathrm{hPa}$ and below, every station shows warming in most or all data sets (Figure 3). It is notable that no data set depicts a significant winter cooling trend at any station at $300 \mathrm{hPa}$ or below (Figure 5). Averaged across the data sets, the strongest tropospheric warming trends are found at McMurdo (Figure 3); however, this partly reflects warming of up to $1^{\circ} \mathrm{C}$ decade $^{-1}$ that is unique to HadAT2 and this location.

[26] Winter temperature trends for $00 \mathrm{z}$ and $12 \mathrm{z}$ READER data individually are broadly comparable to those calculated from daily means, with warming throughout the troposphere, at least at the two stations (Mawson and Mirny) that have sufficient data from both observation times to facilitate a meaningful comparison (auxiliary material Figure S3).

\subsubsection{Spring}

[27] Strong stratospheric cooling can be identified at all stations and in all data sets during spring (Figure 4). The maximum cooling is at 50 or $100 \mathrm{hPa}$ in all cases. Many data sets, stations and levels show cooling trends of magnitudes greater than $-1{ }^{\circ} \mathrm{C}$ decade ${ }^{-1}$. The largest individual trend, a cooling of over $-3^{\circ} \mathrm{C}$ decade ${ }^{-1}$, is found at $50 \mathrm{hPa}$ at McMurdo in the IUK data set. Averaging across all available data sets at a particular level and station, the strongest stratospheric cooling is found at Mawson at $50 \mathrm{hPa}$. The cooling trends at 50,100 and $150 \mathrm{hPa}$ are significant in the majority of data sets and at all stations (Figure 5).

[28] Tropospheric warming is apparent at most stations and in most data sets, but with spatially varying magnitude (Figure 4). The strongest trends are found at McMurdo and Amundsen Scott. Statistically significant warming at $500 \mathrm{hPa}$ and below is found in at least three data sets for Halley, 


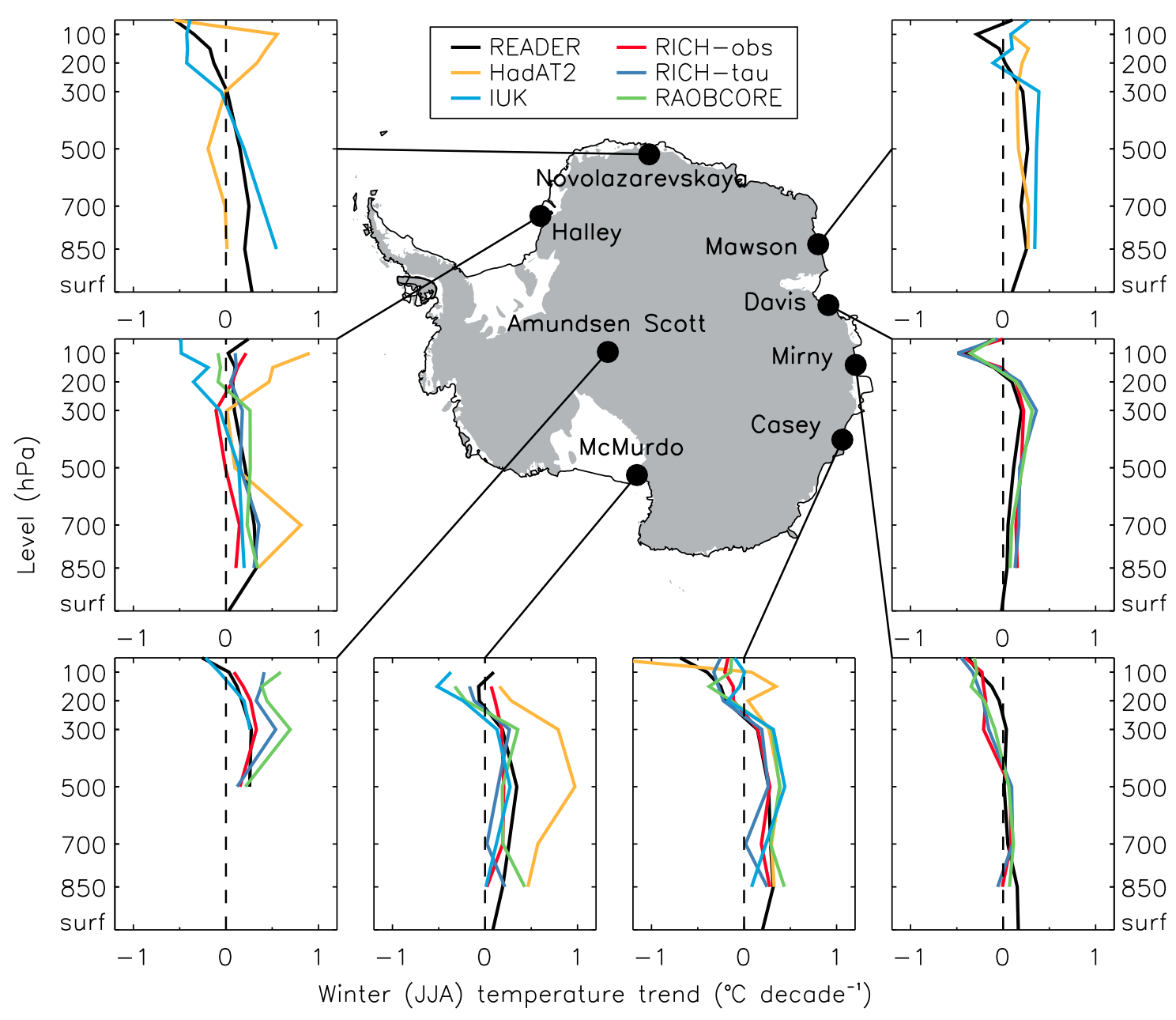

Figure 3. Same as Figure 1, but for winter (June-August) air temperature trends.

Amundsen Scott, McMurdo and Casey (Figure 5). The other stations show no significant tropospheric trends in any of the data sets considered, with the exceptions of HadAT2 that depicts significant $500 \mathrm{hPa}$ cooling at Novolazarevskaya and IUK that shows a significant $850 \mathrm{hPa}$ cooling at Mawson.

[29] Comparing spring trends for $00 \mathrm{z}$ and $12 \mathrm{z}$ separately, it can be seen that the stratospheric cooling appears stronger in the READER data at $12 \mathrm{z}$ than at $00 \mathrm{z}$ for five of the eight stations (auxiliary material Figure S4). These are the U.S. stations, Amundsen Scott and McMurdo, and the Australian stations, Casey, Davis and Mawson. At Mirny the trends are comparable between $12 \mathrm{z}$ and $00 \mathrm{z}$ and at two stations there are insufficient data at both observations times to enable comparison. Again, these trend differences between observations times must be interpreted with caution. The U.S. stations only have $12 \mathrm{z}$ data during the summer observing periods and the Australian stations likewise during earlier part of their records (prior to 1988, 1989, and 1979 for Casey, Davis and Mawson, respectively). The summer observing regimes at these stations usually start in October, so $12 \mathrm{z}$ data for September is often missing from spring (SON) means. This could bias the $12 \mathrm{z}$ trends toward stronger cooling if in reality the cooling has been stronger in the latter part of the spring. However, inclusion of the $12 \mathrm{z}$ (when and where available) in the daily means does not appear to influence (or potentially bias) the trends based on daily means, which very closely follow the $00 \mathrm{z}$ trends (auxiliary material Figure S4; except for at Halley which has no $00 \mathrm{z}$ data).

\subsubsection{Multistation Means}

[30] Figure 6 shows the vertical profiles of the multistation mean air temperature trends. For the READER data we simply averaged the time series from all eight stations. Since none of the homogenized radiosonde data sets have data for all eight stations, it was not possible to create comparable multistation mean time series for each homogenized data set separately. Therefore, we first averaged across all the homogenized data sets available at each station (hereafter we refer to this mean of the homogenized data sets as HOMOG) and then averaged across all eight stations. Note for both READER and HOMOG, the multistation means for 850 and $700 \mathrm{hPa}$ are only based on seven stations since there are no data at Amundsen Scott at these levels.

[31] In the stratosphere both READER and HOMOG show multistation mean cooling in all seasons, but with strong seasonality. The spring stratospheric cooling trends are the largest of any season and level. In spring and summer the multistation mean cooling is statistically significant at 50, 100, 150 and $200 \mathrm{hPa}$ in both READER and HOMOG. In autumn and winter only the $50 \mathrm{hPa}$ cooling is significant 


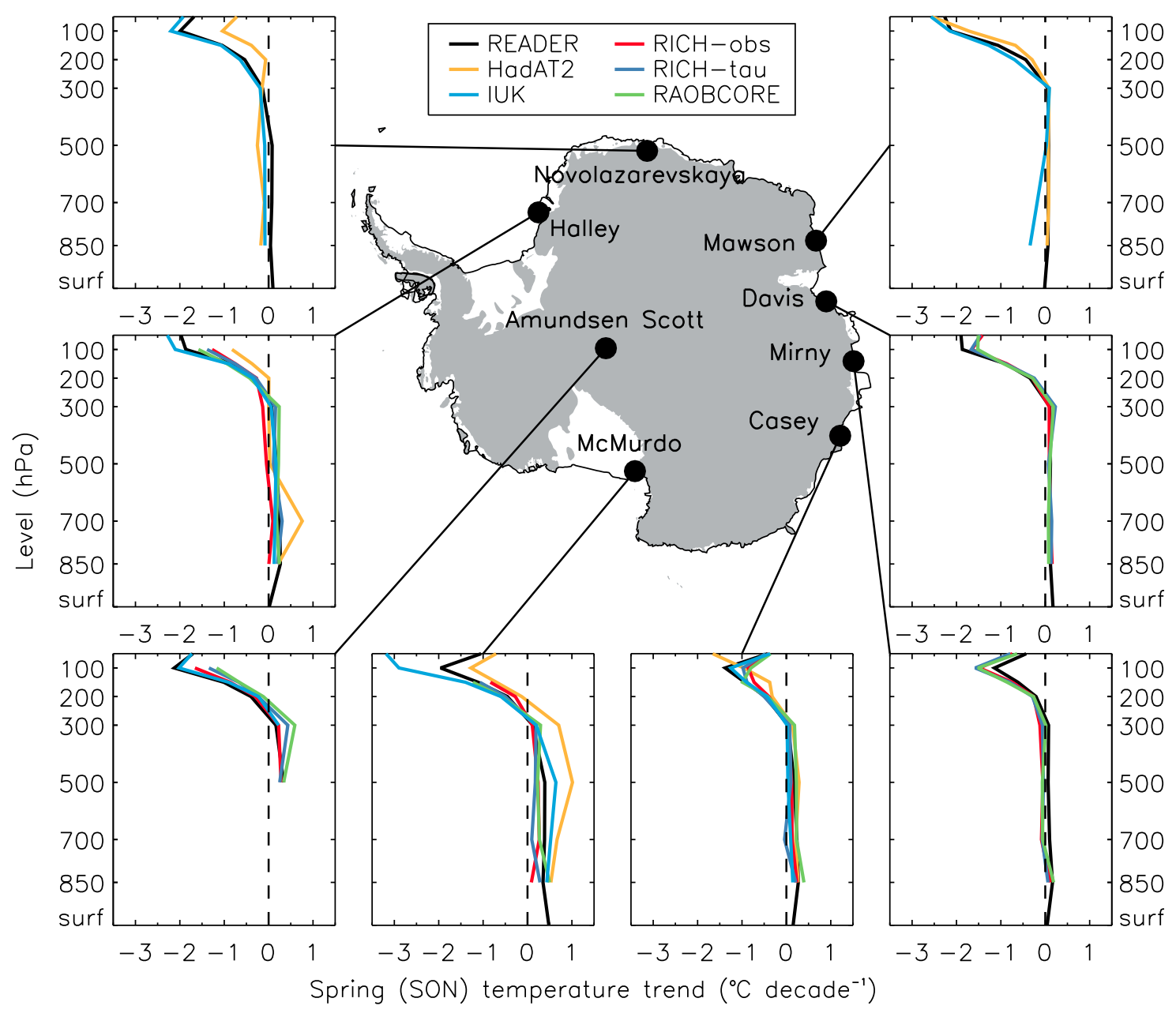

Figure 4. Same as Figure 1, but for spring (September-November) air temperature trends.

in both. The fact that the maximum cooling trends are higher in spring $(50-100 \mathrm{hPa})$ than in summer $(100-150 \mathrm{hPa})$ is consistent with the downward propagation of the trends seen in earlier studies [e.g., Thompson and Solomon, 2002]. In the troposphere there is warming in all seasons. The warming is relatively vertically uniform in winter and spring and is statistically significant in both READER and HOMOG at 500,700 and $850 \mathrm{hPa}$. In summer and autumn there is predominantly mid-tropospheric warming, significant in both READER and HOMOG at $500 \mathrm{hPa}$. The surface trends are weaker than those aloft and are not significant in any season. However, none of the stations analyzed here are located on the Antarctica Peninsula or in West Antarctica where the surface temperature trends have been most pronounced [e.g., Turner et al., 2005; O'Donnell et al., 2011].

\subsection{Summary}

[32] Figures 1 to 4 have revealed substantial uncertainty between Antarctic upper-air trend estimates from different data sets. While this uncertainty cannot be ignored, it is important to stress that there are relatively few seasons, stations or levels that display significant disagreement (in the sense that there are significant trends of both sign) between the various data sets (Figure 5). Those that do are found predominantly in the lower stratosphere during autumn and winter. One possible explanation for this is less raw data, as in these cold seasons, radiosonde balloons are more likely to burst before reaching the stratosphere. In the majority of cases there is agreement on the sign of the trend (if not on its significance), or agreement that there is no significant trend. There are, however, differences in the statistical significance of the trends at an individual station scale depending on the data set used. The few instances where all data sets considered showed significant trends of the same sign are almost exclusively found in the stratosphere and mostly during spring and summer, when the trends (cooling) are largest. Nevertheless, at many stations, seasons and levels, significant trends in one data set are corroborated by significant trends of the same sign in other data sets (if not in all of them). Taking this wealth of information into account, a vertical trend profile characterized by stratospheric cooling, with a marked seasonal cycle, and tropospheric warming emerges (Figure 5).

[33] Furthermore, although there sometimes are significant trend differences between the various data sets at the local scale (that of a single station), Figure 6 shows that at the continental scale, both the trend magnitudes and their associated statistical significance are in close agreement between READER and HOMOG. This gives us high confidence that the broad-scale spring and summer stratospheric 


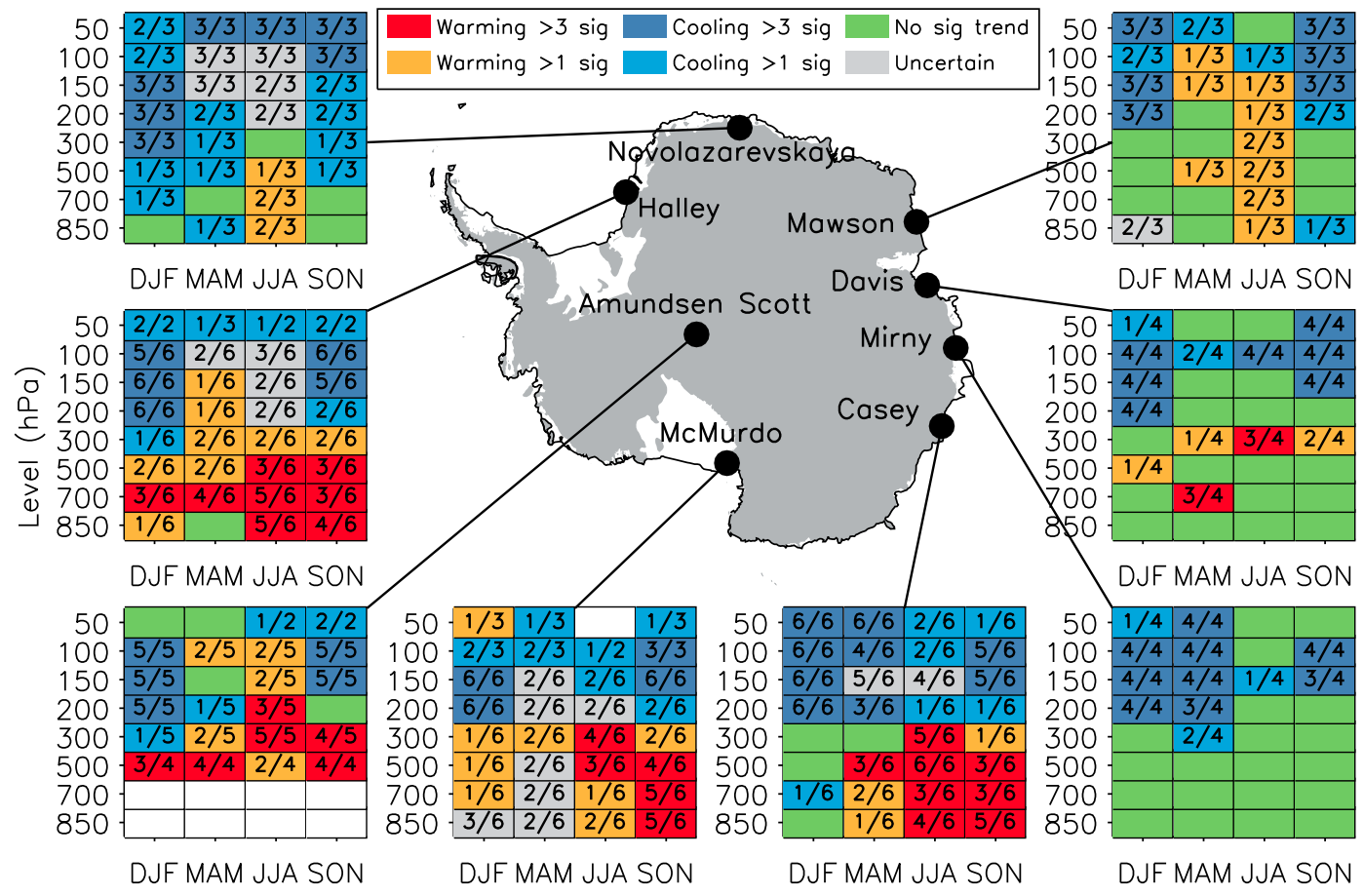

Figure 5. Statistical significance of radiosonde temperature trends. Each colored box corresponds to a set of temperature trends from multiple data sources for a particular season, vertical level and Antarctic station. The color scheme is as follows: dark red, three of more data sets show statistically significant $(\mathrm{p}<$ 0.05) warming and none show significant cooling; light red, at least one data set shows significant warming and none show significant cooling; dark blue, three of more statistically significant cooling trends and no significant warming trend; light blue, at least one significant cooling trend and no significant warming trend; green, no significant trend of either sign; gray, significant trends of both sign; white, insufficient data to calculate a trend. The digits show the number of data sets that depict statistically significant trends.

cooling and the year-round tropospheric warming are real and do not result from temporal inhomogeneities in the radiosonde observations. We note, however, that READER overestimates the mid-tropospheric warming (by $25-35 \%$ at
$500 \mathrm{hPa}$ ) compared to HOMOG in all seasons except winter, overestimates the lower stratospheric cooling (by $10-15 \%$ at $150 \mathrm{hPa}$ ) in spring and summer, and shows significant $100 \mathrm{hPa}$ cooling in autumn and winter that is not seen in HOMOG.

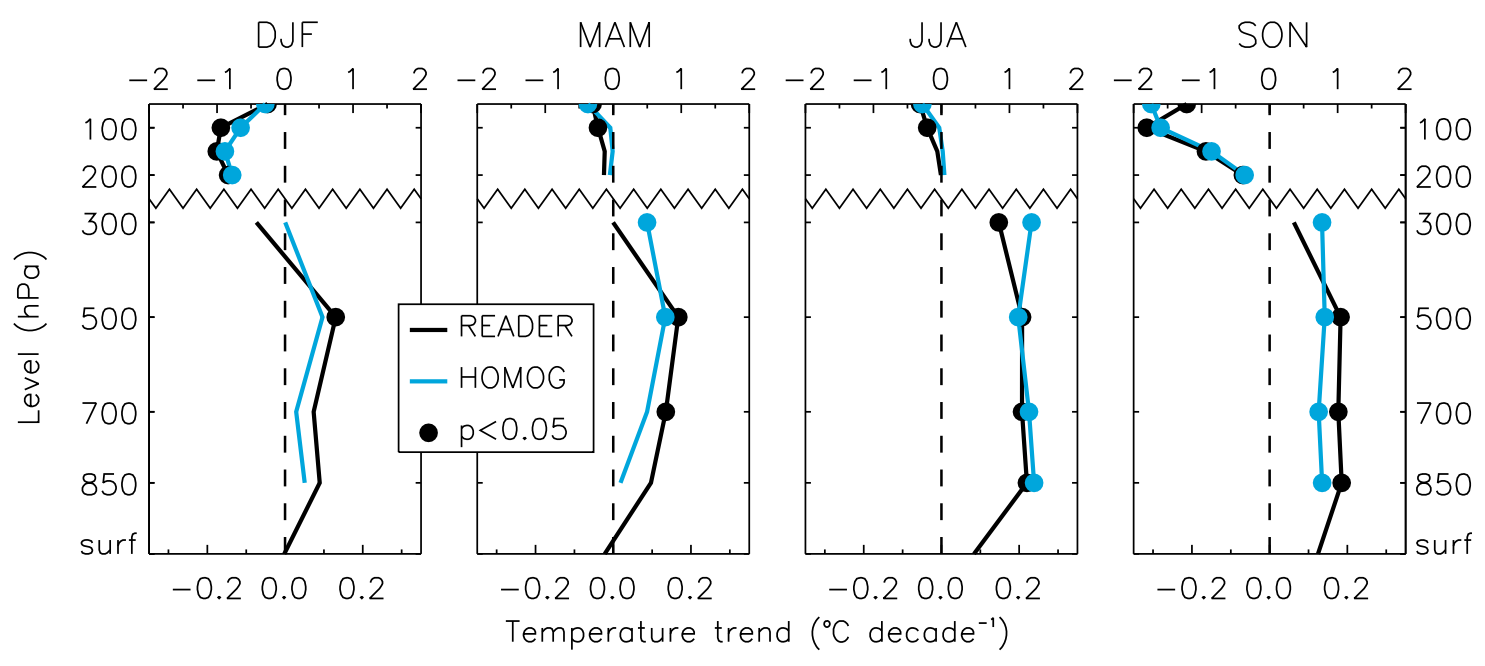

Figure 6. Vertical profiles of seasonal-mean air temperature trends averaged across the eight Antarctic stations. Trends are shown for READER (black) and the average of five homogenized radiosonde data sets (blue). Statistically significant $(\mathrm{p}<0.05)$ trends are shown by colored dots. Note the differing horizontal scales above and below $250 \mathrm{hPa}$. 

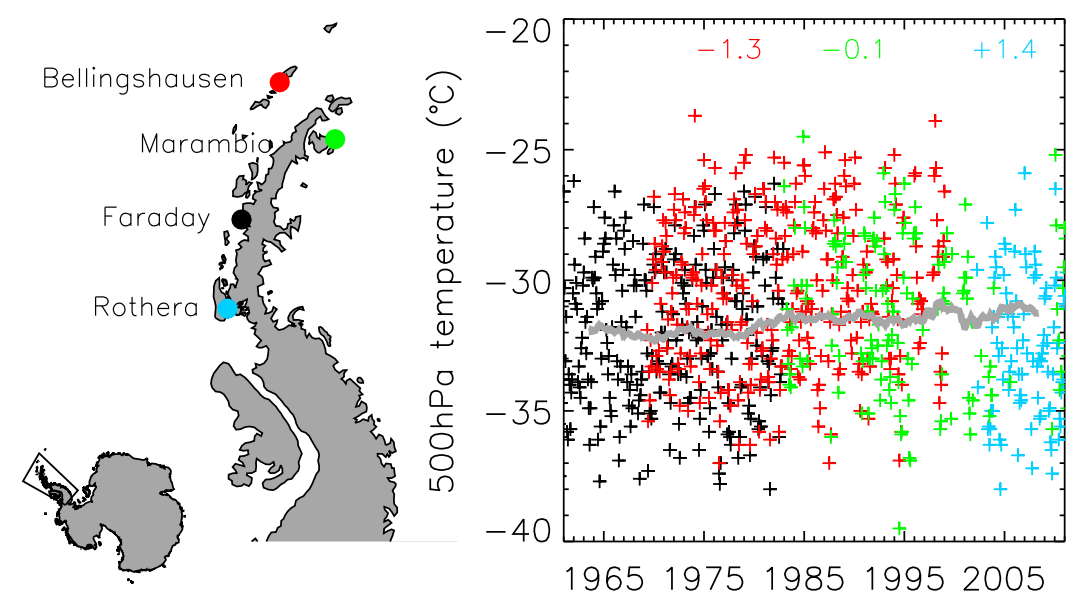

Figure 7. Example of the construction of the merged Antarctic Peninsula record. Each cross denotes a (unadjusted) monthly mean $500 \mathrm{hPa}$ temperature value taken from four stations on the Antarctic Peninsula (locations and colors given on map). The colored numbers show the adjustments used in the cross-calibration (see text). The thick gray line shows the merged (adjusted) time series, with a 60-month (5-year) smoothing applied.

In section 3, these differences are considered further by performing pan-Antarctic reconstructions based on both the READER and HOMOG station trends.

\section{Spatial Reconstructions}

[34] In the following sections we introduce and present the first spatial reconstructions of pan-Antarctic temperature change aloft. Section 3.1 describes the reconstruction methods, including steps taken to combine incomplete observational records at nearby stations (section 3.1.1); validate multiple atmospheric reanalysis data sets and select the best product to use in our reconstructions (section 3.1.2); using the best reanalysis, derive statistical models that describe the spatiotemporal variability of upper air temperature (3.1.3.); and to estimate errors in these statistical models (3.1.4.). The observed station trends (from section 2) are then used in conjunction with the statistical models to create pan-Antarctic temperature trend reconstructions for the mid-troposphere $(500 \mathrm{hPa})$ and lower stratosphere $(150 \mathrm{hPa})$, which are presented in section 3.2. The 500 and $150 \mathrm{hPa}$ levels were chosen as they correspond to altitudes of overall maximum tropospheric warming and stratospheric cooling. Our reconstructions supplement those which have been constructed for surface temperature changes [Comiso, 2000; Doran et al., 2002; Chapman and Walsh, 2007; Monaghan et al., 2008; Steig et al., 2009; O'Donnell et al., 2011].

\subsection{Reconstruction Methods}

\subsubsection{Merging Incomplete Records}

[35] In comparison to surface-based reconstructions, there are fewer observations to guide our reconstructions. This is because there are fewer Antarctic stations providing upper-air measurements than there are providing surface observations. However, the horizontal scales of temperature variability are larger with increasing height and therefore, fewer stations are required to characterize the spatial variability of upper-air temperature [e.g., McCarthy, 2008]. The eight core stations provide good coverage around the coast of East Antarctica. However, only one station is located on the high Antarctic plateau and we use no stations on the Antarctic Peninsula, which may limit the quality of reconstructions in these areas. As mentioned earlier, there are a number of stations (Table 1; Category 1 stations) in these regions that have incomplete data records over the period 1961-2010. To improve our station distribution, we have undertaken a process of iterative crosscalibration and merging of incomplete records from nearby stations. In the Antarctic Peninsula region we have combined station records from Faraday (1961-1982), Bellingshausen (1969-1998), Marambio (1983-2010) and Rothera (2002-2010) (see locations in Figure 7). Johanson and Fu [2007] identified problems with the Bellingshausen radiosonde record in 1992 and 1995 so we exclude these two years in our calculations.

[36] First, we calculated the correlations between the station temperature time series during the periods of overlap. All the four stations were highly correlated: at $500 \mathrm{hPa}$, correlations of $0.94,0.83$ and 0.87 for Faraday-Bellingshausen, Bellingshausen-Marambio and Marambio-Rothera, respectively, and at $150 \mathrm{hPa}$, correlations of 0.99 for all three station combinations. Second, we calculated the climatological means at Faraday and Bellingshausen during the period of overlap. The difference in these means was subtracted from the Bellingshausen time series. Third, we calculated the climatological means at Bellingshausen (with adjustment to Faraday applied) and Marambio during the period of overlap. The difference in these means was subtracted from the Marambio time series. Fourth, the Rothera time series was adjusted to that at Marambio in exactly the same way. Last, during the periods of overlap between records from different stations, data from the reference station (in this case, Faraday) was preferentially chosen for inclusion in the merged record, or if data from the reference station was unavailable, then the nearest station (to the reference station) with data available was used. This results in a single time series covering the full period 1961-2010 


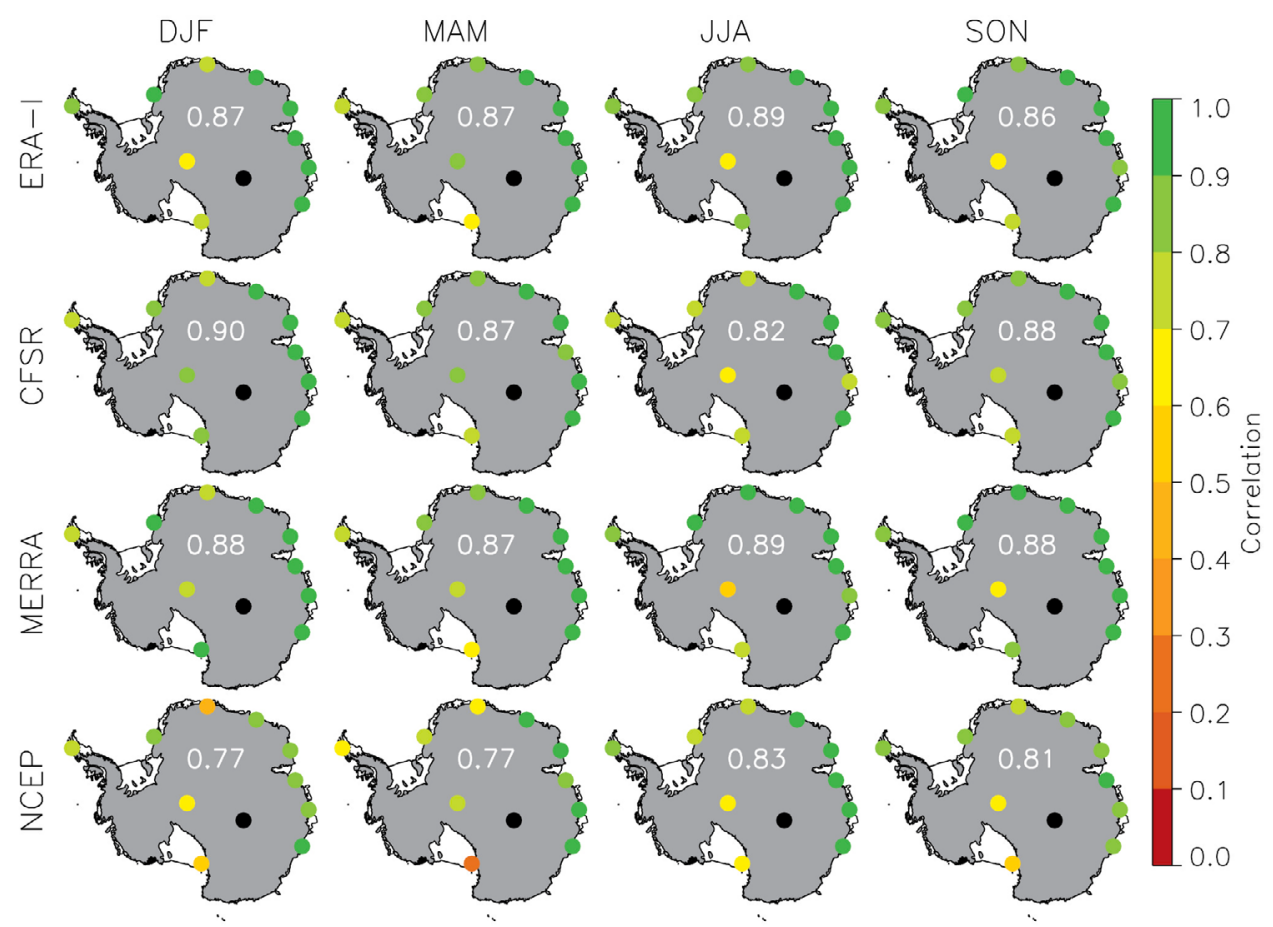

Figure 8. Correlations between observed and reanalysis $500 \mathrm{hPa}$ temperatures for (left to right) the four seasons and (top to bottom) four different reanalysis data sets. Each colored dot corresponds to correlation between the observed time series at a particular Antarctic station (1979-2010) and the corresponding time series from a reanalysis grid-box containing that station. Black dots indicate insufficient data to accurately calculate the correlation. The white numbers show the correlations averaged across the stations.

calibrated relative to Faraday (Figure 7). We consider the location of this merged record to correspond to that of Faraday and the merged record is hereafter referred to as "Faraday" All the above steps were performed on the raw READER monthly means and separately for the 500 and $150 \mathrm{hPa}$ levels. Temperature anomalies and seasonal means thereof were calculated as before (see section 2.1.1) after the data had been calibrated and merged.

[37] The process was repeated to merge data from two stations on the Enderby Land coast: Molodeznaja (19641998) and Syowa (1968-2010). These two stations are located approximately $300 \mathrm{~km}$ apart and their temperature time series are very highly correlated during the period of overlap: 0.97 for both 500 and $150 \mathrm{hPa}$. In this case the calibration was relative to Syowa and, therefore, the location of the merged series is considered to be that of Syowa and the merged record is hereafter referred to as "Syowa."

[38] We have also merged data from two stations on the Antarctic high plateau: Vostok (1961-1992) and Concordia (2006-2010), which are $560 \mathrm{~km}$ apart. Because the records from these stations do not overlap, a third independent station (with a record spanning both the Vostok and Concordia years of operation), had to be used to infer the differences in climatological means. We used data from Amundsen Scott for this purpose. Although Amundsen Scott is relatively far from either station, the temperature time series were still highly correlated: at $500 \mathrm{hPa}$, correlations of 0.90 and 0.87 for Vostok-Amundsen Scott and Concordia-Amundsen Scott respectively, and at $150 \mathrm{hPa}, 0.99$ and 0.98 , respectively. The adjustment applied to the Concordia data (A2) was calculated as:

$$
\mathrm{A} 2_{2006-2010}=\left(\mathrm{T}_{1961-1992}-\mathrm{T} 3_{1961-1992}\right)-\left(\mathrm{T} 2_{2006-2010}-\mathrm{T} 3_{2006-2010}\right),
$$

where $\mathrm{T} 1, \mathrm{~T} 2$ and $\mathrm{T} 3$ are the climatological means at Vostok, Concordia and Amundsen Scott, respectively and subscripts denote the averaging period. The Amundsen Scott data were only used to calculate the adjustment and were not included in the merged time series (i.e., the merged record has missing data from 1993 to 2005). In this case the calibration was relative to Vostok and therefore, the location of the merged series is considered to be that of Vostok and the merged record is hereafter referred to as "Vostok."

[39] We have performed reconstructions with both the core 8station network and an expanded network that includes the core stations plus the "Faraday" "Syowa" and "Vostok" records.

\subsubsection{Reanalysis Selection}

[40] Our reconstruction approach requires the use of temperature fields from an atmospheric reanalysis in order to develop a statistical model that describes the spatiotemporal variability of upper-air temperatures. Before proceeding further, we consider whether atmospheric reanalyses can accurately capture the upper-air temperature variability observed at the Antarctic stations. We have examined temperature fields from four different atmospheric reanalyses: the NASA Modern Era Retrospective-analysis for Research and Applications (MERRA) product [Rienecker et al., 2011], 
the NCEP Climate Forecast System Reanalysis (CFSR) [Saha et al., 2010], the ECMWF Interim reanalysis (ERA-I) [Dee et al., 2011] and the NCEP-NCAR reanalysis (NCEP) [Kalnay et al., 1996].

[41] Figure 8 shows seasonal correlations between the $500 \mathrm{hPa}$ radiosonde temperature observations and the reanalyses sub-sampled at $500 \mathrm{hPa}$ and at the grid-boxes containing the stations, for the period 1979-2010. The correlations are generally high $(>0.8)$ and exhibit little seasonality. There is a tendency for highest correlations at stations along the East Antarctic coast and lower correlations (0.6-0.7) at Amundsen Scott, "Faraday" and McMurdo. Only a few stations and seasons show correlations below 0.6 , and most of these are found in NCEP (the oldest and lowest resolution product). Other authors have also found that the newer, higher-resolution reanalyses are more realistic over Antarctica than older products [Bromwich et al., 2011; Bracegirdle and Marshall, 2012]. While the largely high correlations are reassuring, we are mindful that the validation data set is not independent from the reanalyses: the radiosonde data have been assimilated during the reanalysis process. High correlations at the station locations do not necessarily imply that the reanalyses perform well in regions distant from the stations. However, we argue that a reanalysis that is well-constrained by observations is more likely to exhibit realistic temperature variability over larger areas of the Antarctic.

[42] There are differences in performance between the reanalyses which can inform a decision on the most appropriate reanalysis to use. Averaged over the seasons and stations, the best performing reanalysis at $500 \mathrm{hPa}$ is MERRA (0.87), then CFSR and ERA-I $(0.86)$ and the worst performing reanalysis is NCEP $(0.79)$. The equivalent correlations at $150 \mathrm{hPa}$ are $0.85,0.85,0.88$ and 0.86 for MERRA, CFSR, ERA-I and NCEP, respectively (not shown). We have undertaken reconstructions with the three reanalyses that best-perform overall: MERRA, ERA-I and CFSR. In the main manuscript we focus on the MERRAbased reconstructions; however, reconstructions based on ERA-I and CFSR are shown in Figure 11 and in the auxiliary material. As will be discussed in section 3.2, the reconstructions are only weakly sensitive to the choice of reanalysis used to derive the statistical models.

\subsubsection{Model Derivation}

[43] We derive sixteen statistical models: eight using the core station network, one for each season for both 500 and $150 \mathrm{hPa}$, and eight using the expanded station network, one for each season for 500 and $150 \mathrm{hPa}$. In each case the procedure was exactly the same. The reanalysis fields were subsampled at the grid-boxes containing the stations. We then performed multiple linear regression of these sub-sampled time series against the Antarctic-wide seasonal-mean temperature fields. The multiple linear regression gives a statistical model of the form,

$$
\mathrm{y}_{\mathrm{i}, \mathrm{j}, \mathrm{t}}=\mathrm{a}_{1, \mathrm{i}, \mathrm{j}} \mathrm{x}(\mathrm{sub})_{1, \mathrm{t}}+\mathrm{a}_{2, \mathrm{i}, \mathrm{j}} \mathrm{x}(\mathrm{sub})_{2, \mathrm{t}}+\ldots+\mathrm{a}_{\mathrm{n}, \mathrm{i}, \mathrm{j}} \mathrm{x}(\mathrm{sub})_{\mathrm{n}, \mathrm{t}}+\mathrm{c},
$$

where $y$ is the predicted seasonal-mean temperature at longitude $i$, latitude $j$ and year $t ; a_{1}$ to $a_{n}$ are the regression coefficients; $x(s u b)_{1}$ to $x(s u b)_{n}$ are the temperatures at the sub-sampled reanalysis grid-boxes; and $c$ is a constant. The regression was performed using reanalysis data from 1979 to 2010. The $a_{1}$ to $a_{n}$ and $c$ terms from equation (2) can be used in conjunction with the observed temperature anomalies at the stations, $x(o b s)_{1, \mathrm{t}}$ to $x(o b s)_{n, t}$, to reconstruct the temperature evolution over the whole Antarctic for the full 50-year period 1961-2010; as,

$$
\operatorname{REC}_{\mathrm{i}, \mathrm{j}, \mathrm{t}}=\mathrm{a}_{1, \mathrm{i}, \mathrm{j}} \mathrm{x}(\mathrm{obs})_{1, \mathrm{t}}+\mathrm{a}_{2, \mathrm{i}, \mathrm{j}} \mathrm{x}(\mathrm{obs})_{2, \mathrm{t}}+\ldots+\mathrm{a}_{\mathrm{n}, \mathrm{i}, \mathrm{j}} \mathrm{x}(\mathrm{obs})_{\mathrm{n}, \mathrm{t}}+\mathrm{c} .
$$

[44] To reconstruct the temperature trends over the whole Antarctic, the time derivative of equation (3) was taken and re-written in the form,

$$
\Delta \mathrm{REC}_{\mathrm{i}, \mathrm{j}}=\mathrm{a}_{1, \mathrm{i}, \mathrm{j}} \Delta \mathrm{x}(\mathrm{obs})_{1}+\mathrm{a}_{2, \mathrm{i}, \mathrm{j}} \Delta \mathrm{x}(\mathrm{obs})_{2}+\ldots+\mathrm{a}_{\mathrm{n}, \mathrm{i}, \mathrm{j}} \Delta \mathrm{x}(\mathrm{obs})_{n},
$$

where $a_{1}$ to $a_{n}$ come from equation (2), $\Delta x(o b s)_{1}$ to $\Delta(o b s)_{n}$ are the observed temperature trends (1961-2010) at the stations and $\triangle R E C$ is the reconstructed temperature trend at longitude $i$ and latitude $j$.

[45] If there were no missing data, equation (4) would be exactly the same as calculating a reconstructed time series via equation (3) and then calculating the linear trend in this reconstructed time series. However, because there are missing data is it advantageous to reconstruct only the linear trends (via equation (4)) and not the full temperature evolution (via equation (3)). This is best illustrated through an example. Suppose station $X$ has missing data from years 5 9, station Y has missing data from years $15-19$ and station Z has missing data from years $25-29$. By calculating the trends first, we account for the five years of missing data in each time series at a station-per-station basis and then have a complete set of temperature trends to input into equation (4). Conversely if we carried out the reconstruction first, missing data at any station would inhibit a reconstruction for that year (see equation (3)). In our example, the reconstructed time series would have fifteen missing values. Hypothetically, if ten stations had five missing values each, at different times to the other stations, then the reconstructed time series would have missing values for all fifty years. In practice this is unlikely as we have selected stations with near-complete records; however, if we did reconstruct temperature time series (before calculating trends therein), then missing data would accumulate and become more problematic. This is not to say that missing data will have no influence on the reconstructed trends, simply it is advantageous to minimize their influence in the manner just described. Thus, we calculate the observed station trends first and then reconstruct Antarctic-wide trends using equation (4).

\subsubsection{Error Estimation}

[46] To quantitatively test the ability of our statistical models to reconstruct pan-Antarctic temperature trends, we attempt to reconstruct the trends in the reanalyses (19792010) using our statistical models by

$$
\Delta \mathrm{REC}_{\mathrm{i}, \mathrm{j}}=\mathrm{a}_{1, \mathrm{i}, \mathrm{j}} \Delta \mathrm{x}(\mathrm{sub})_{1}+\mathrm{a}_{2, \mathrm{i}, \mathrm{j}} \Delta \mathrm{x}(\mathrm{sub})_{2}+\ldots+\mathrm{a}_{\mathrm{n}, \mathrm{i}, \mathrm{j}} \Delta \mathrm{x}(\mathrm{sub})_{n},
$$

where $\Delta x(s u b)_{1}$ to $\Delta x(s u b)_{n}$ are the temperature trends at the 


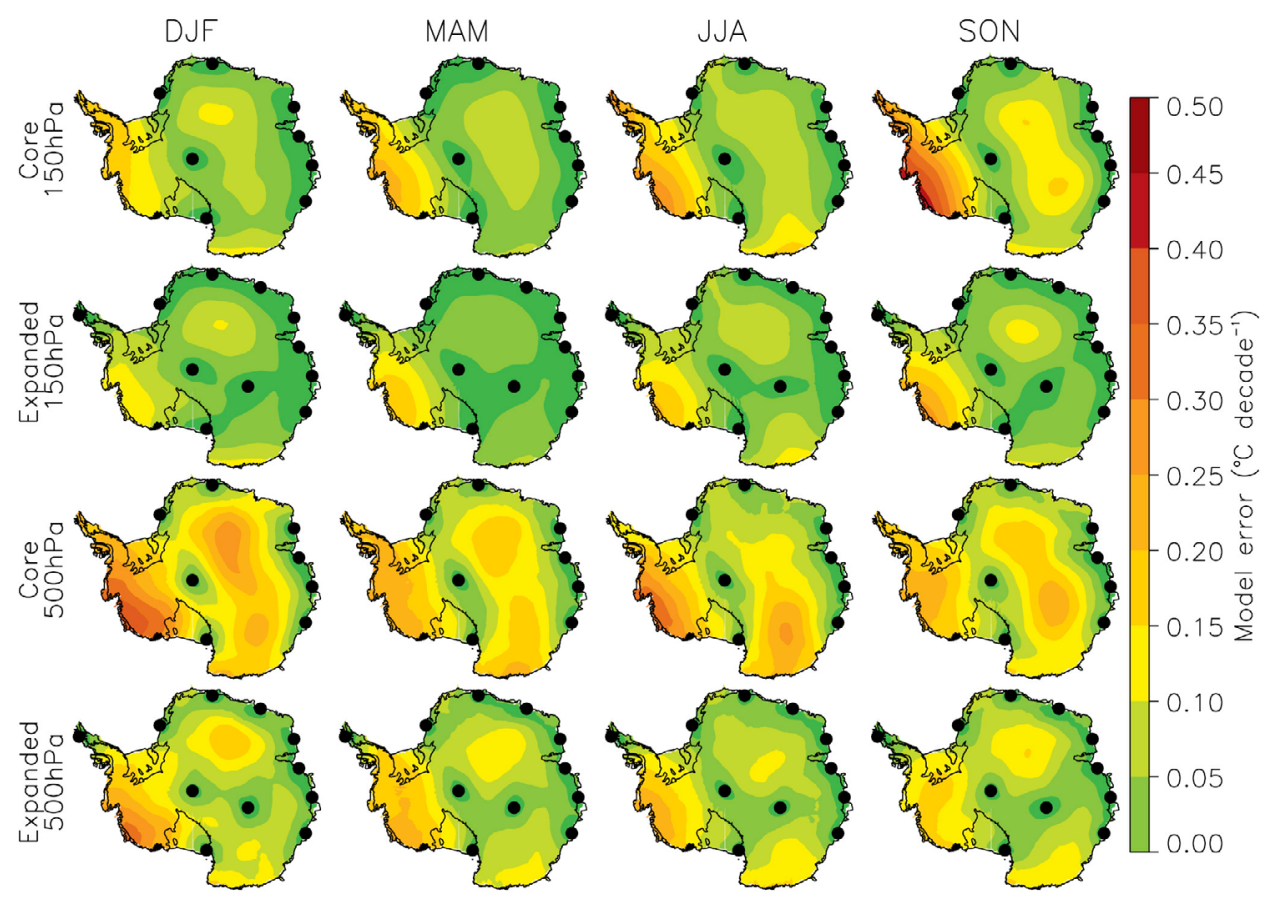

Figure 9. Statistical model error $\left({ }^{\circ} \mathrm{C}\right.$ decade $\left.^{-1}\right)$ estimated from the ninety-fifth percentile (absolute) error obtained in ten thousand iterations of the MERRA-based models. Errors were estimated separately for (left to right) the four seasons, (first and second rows) $150 \mathrm{hPa}$ and (third and fourth rows) $500 \mathrm{hPa}$ and for models derived using eight stations (first and third rows) and eleven stations (second and fourth rows). The locations of the stations are shown by black dots.

sub-sampled reanalysis grid-boxes. If the statistical models were perfect, then the reconstructed trends would match the reanalysis trends at each grid-box, i.e.,

$$
\Delta \operatorname{REC}_{\mathrm{i}, \mathrm{j}}=\Delta x_{\mathrm{i}, \mathrm{j}} .
$$

[47] Therefore, we define the absolute model error (AME) as,

$$
\mathrm{AME}_{\mathrm{i}, \mathrm{j}}=\left|\Delta \mathrm{REC}_{\mathrm{i}, \mathrm{j}}-\Delta \mathrm{x}_{\mathrm{i}, \mathrm{j}}\right| .
$$

[48] This provides one value per grid-box of the AME (in units of ${ }^{\circ} \mathrm{C}$ decade ${ }^{-1}$ ) based on the period $1979-2010$. However, the AME is likely to be sensitive to the magnitudes of the trends and the trends are dependent on the time period. Therefore, the errors based on the period 1979-2010 may not be representative of the errors over other periods. To obtain robust estimates of model error, we performed the error estimation process ten thousand times using randomly shuffled time series. The seasonal-mean reanalysis fields were randomized consistently at all grid points to preserve the spatial variability, but the year-to-year variability (and hence, trends) was altered in each iteration. For each iteration, the randomized reanalysis fields were sub-sampled, pan-Antarctic temperature trends reconstructed from these sub-sampled points using our statistical models, and then the AME calculated relative to the trends in the randomized reanalysis fields at all grid points. Our robust estimate of the Monte Carlo error (MCE) at each grid-box is provided by the ninety-fifth-percentile of the ten thousand cases.
[49] Figure 9 shows the MCE for each of the sixteen statistical models. By definition the MCE is zero at the gridboxes containing stations and unsurprisingly, the errors generally increase with distance from the stations. The errors are larger over West Antarctica and increase toward the Amundsen Sea coast. The maximum errors are found along this coast: up to $0.3-0.4^{\circ} \mathrm{C}$ decade $^{-1}$ at $150 \mathrm{hPa}$ in spring and $500 \mathrm{hPa}$ in summer. The errors increase from the coast of East Antarctica toward the high-elevation plateau, especially at $500 \mathrm{hPa}$. There is also a tendency for higher errors on the coast between 120 and $180^{\circ} \mathrm{E}$ than anywhere else around the coast of East Antarctica.

[50] Aside from these regional differences, there are more subtle differences between the levels and seasons, and between models based on the core and expanded networks. In most instances, the errors are smaller at $150 \mathrm{hPa}$ (mostly under $0.15^{\circ} \mathrm{C}$ decade $^{-1}$ ) than at $500 \mathrm{hPa}$. This is consistent with the hypothesis that the horizontal scales of temperature variability increase with increasing altitude. The obvious exception to this is the West Antarctic in spring, where the errors are largest at $150 \mathrm{hPa}$. In terms of seasonality, the errors are largest in spring, but comparable in the other seasons at $150 \mathrm{hPa}$. At $500 \mathrm{hPa}$, the errors are largest in summer and generally comparable in the other seasons. The inclusion of the three extra stations in the expanded network models appreciably reduces the errors well beyond the immediate vicinity of the extra stations. These differences are especially pronounced at $500 \mathrm{hPa}$ where, for example, the errors are reduced by up to one half over much of West Antarctica, presumably because of the inclusion of "Faraday" on the Antarctic Peninsula. The addition of "Vostok" 


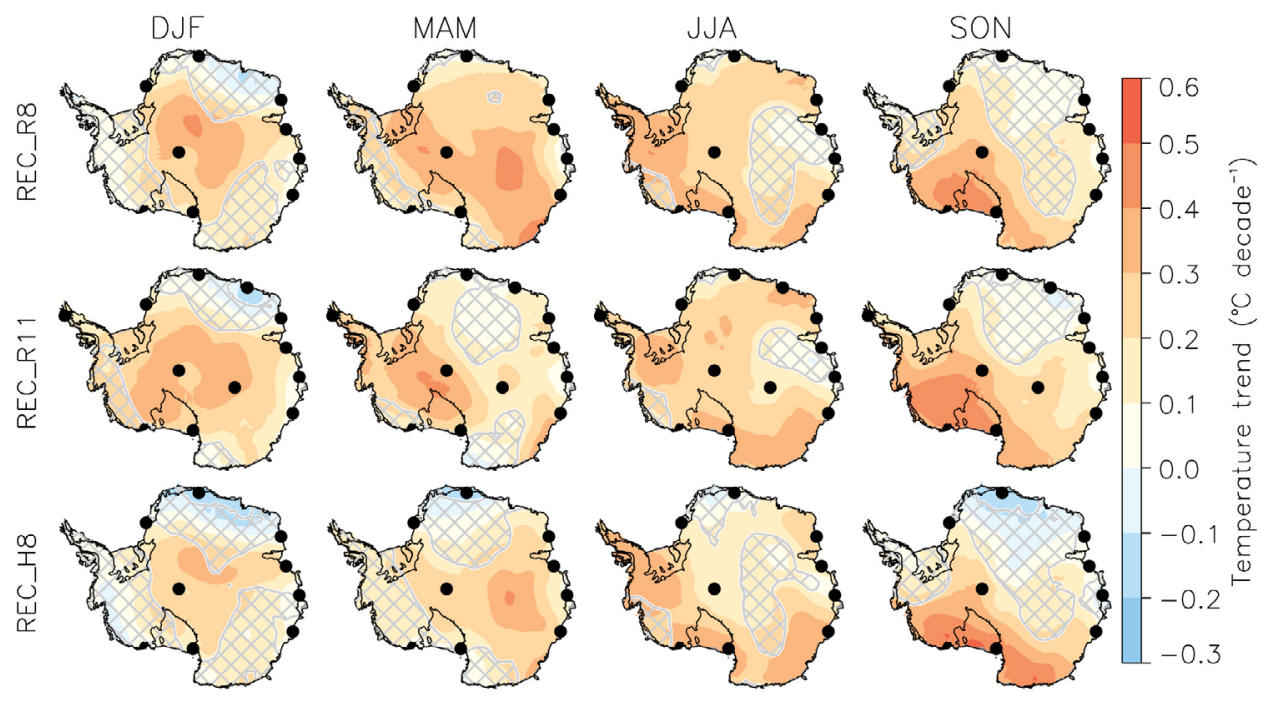

Figure 10. Reconstructed Antarctic $500 \mathrm{hPa}$ temperature trends $\left({ }^{\circ} \mathrm{C}\right.$ decade $\left.{ }^{-1}\right)$ for (left to right) each season and (top to bottom) each MERRA-based reconstruction. Gray cross-hatching indicates that the reconstructed trends are smaller than the estimated statistical model error. The black dots show the locations of the stations that guide the reconstructions.

reduces errors over large parts of high-elevation East Antarctica. With the expanded network, the errors at $500 \mathrm{hPa}$ are mostly under $0.15^{\circ} \mathrm{C}$ decade $^{-1}$, although the errors in West Antarctica remain slightly larger than this.

[51] Statistical models based on ERA-I and CFSR show quantitatively similar MCE and comparable spatial patterns (auxiliary material Figures S5 and S6, respectively) to those from the MERRA-based models that have just been discussed. These MCE estimates will be used in the following section to provide a measure of confidence in our reconstructions.

\subsection{Reconstructed Trends}

[52] We have produced three sets of reconstructions, with each set containing a separate reconstruction for each season and the two levels, 500 and $150 \mathrm{hPa}$. The first set uses the core 8-station network and is guided by the READER observed trends (hereafter, REC_R8). The second set uses the expanded 11-station network and is also guided by the READER observed trends (hereafter, REC_R11). The third set uses the core 8-station network and is guided by the HOMOG observed trends (hereafter, REC_H8).

\subsubsection{Mid-troposphere}

[53] Figure 10 presents all the MERRA-based $500 \mathrm{hPa}$ reconstructions, with gray cross-hatching in regions where the reconstructed trends are smaller than the MCE. All three reconstructions suggest extensive year-round mid-tropospheric warming. The only cooling region is along the coast between Novolazarevskaya and Mawson in summer (and to a lesser extent in autumn and spring in REC_H8 only). Elsewhere, warming trends are ubiquitous. The maximum warming rates are commonly 0.4 to $0.5^{\circ} \mathrm{C}$ decade $^{-1}$, which exceed the estimated model errors. The regions of maximum warming vary by season, but are largely consistent between the reconstructions (with the possible exception of autumn). In summer, largest warming is located over the center of the continent and in winter, over West Antarctica and along the coast between McMurdo and Casey. A robust feature in all three spring reconstructions is a regional warming maximum over the Ross Ice Shelf, and adjacent parts of West and East Antarctica. This spatial pattern is reminiscent of that seen in surface temperature reconstructions over similar time periods [Chapman and Walsh, 2007; Monaghan et al., 2008; Steig et al., 2009; O'Donnell et al., 2011]. Springtime warming over the West Antarctic is one of the most robust features across a number of independent surface temperature reconstructions [Schneider et al., 2012].

[54] Outside these regions just mentioned there is weaker warming (up to $0.3^{\circ} \mathrm{C}$ decade $^{-1}$ ). In some areas this fairly modest warming is still larger than the estimated model errors; however, in others it is not. In particular, model errors exceed the warming rates over much of the continent in summer, over large parts of West Antarctica and Dronning Maud Land in autumn, some areas of the central East Antarctica in winter, and above much of East Antarctica and the Antarctic Peninsula in spring.

[55] In winter, spring and summer, the spatial patterns of reconstructed warming are largely similar in REC_R8 and REC_R11. However, the additional tie-points in RE $\bar{E} C$ R11 (primarily "Vostok" result in less warming over central East Antarctica in autumn. The addition of "Faraday" and "Vostok" in REC_R11 reduces errors in the vicinity of these stations and results in larger areas where the reconstructed trends exceed the model errors, particularly over the Peninsula and adjacent parts of West Antarctica, and over central East Antarctica. The addition of "Syowa" has less impact on the reconstructions. It is also interesting to contrast REC_R8 (based on READER observed trends) and REC_H8 (based on HOMOG observed trends). In general there is close agreement between the two, which lends credence to the veracity of the reconstructed trends. It gives us confidence that the READER-based reconstructions are not strongly influenced by possible inhomogeneities in this data set.

[56] Figures S7 and S8 in the auxiliary material present equivalent $500 \mathrm{hPa}$ trend reconstructions but based on statistical models derived from the ERA-I and CFSR reanalyses, respectively. The reconstructions based on the three 


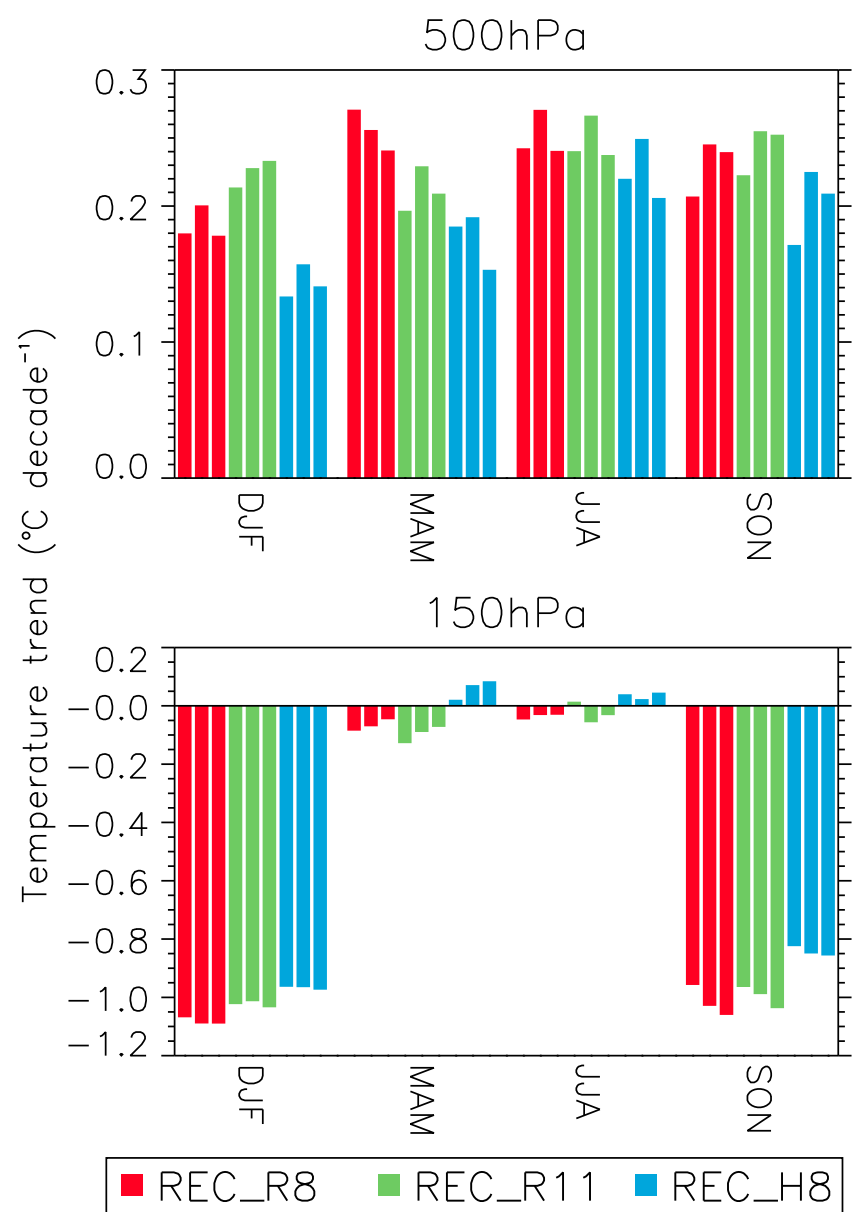

Figure 11. Antarctic-mean seasonal-mean reconstructed temperature trends at (top) $500 \mathrm{hPa}$ and (bottom) $150 \mathrm{hPa}$. Trends from multiple reconstructions are shown by the different colors and within in each colored subset, the three bars correspond to MERRA-, ERA-I- and CFSR-based reconstructions from left to right, respectively. different reanalyses show highly consistent spatial trend patterns and all suggest widespread and year-round midtropospheric warming. The main, but relatively small, differences relate to the trend magnitudes rather than the spatial patterns. The ERA-I-based reconstructions generally show stronger winter warming (by approximately $0.1^{\circ} \mathrm{C}$ decade $^{-1}$ ) than either the MERRA- or CFSR-based reconstructions, and the spring warming over West Antarctica and the Ross Ice Shelf is larger (by approximately $0.1^{\circ} \mathrm{C} \mathrm{decade}^{-1}$ ) in both the ERA-I and CFSR-based reconstructions than in the MERRAbased reconstructions. Thus, there is some evidence to suggest that the MERRA-based reconstructions (Figure 10) may slightly underestimate the mid-tropospheric warming.

[57] Area-weighted Antarctic-mean reconstructed trends are given in Figure 11. In all seasons and all reconstructions there are Antarctic-mean $500 \mathrm{hPa}$ warming trends. The warming rates vary from 0.13 to $0.27^{\circ} \mathrm{C}_{\text {decade }}{ }^{-1}$ depending on the season and reconstruction considered. The seasonality of the warming varies between the reconstructions, due to both differences in the observations used to guide the reconstructions (i.e., differences between REC_R8, REC_R11 and REC_H8) and differences in the reanalyses used to derive the statistical models. As a collective the reconstructions suggest that the largest mid-tropospheric warming has occurred in winter and the weakest warming in summer. For any particular season and using any particular reanalysis, the Antarctic-mean trends in REC_H8 are lower than those in either REC R8 or REC_R 1 1. This is consistent with differences in the multistation means between READER and HOMOG discussed earlier (Figure 6). The Antarctic-mean trends in the ERA-Ibased reconstructions are generally larger than those in either the MERRA- or CFSR-based reconstructions, although this is not always the case (Figure 11).

\subsubsection{Lower Stratosphere}

[58] Figure 12 presents all the $150 \mathrm{hPa}$ reconstructions. Lower stratospheric cooling is continent-wide in spring and summer and is a robust feature in all reconstructions. In these two seasons, the cooling rates exceed the model errors at all grid-boxes. The maximum cooling rates are -1.2 to $-1.4^{\circ} \mathrm{C}$ decade ${ }^{-1}$, approximately three times greater than the maximum mid-tropospheric warming rates. There is

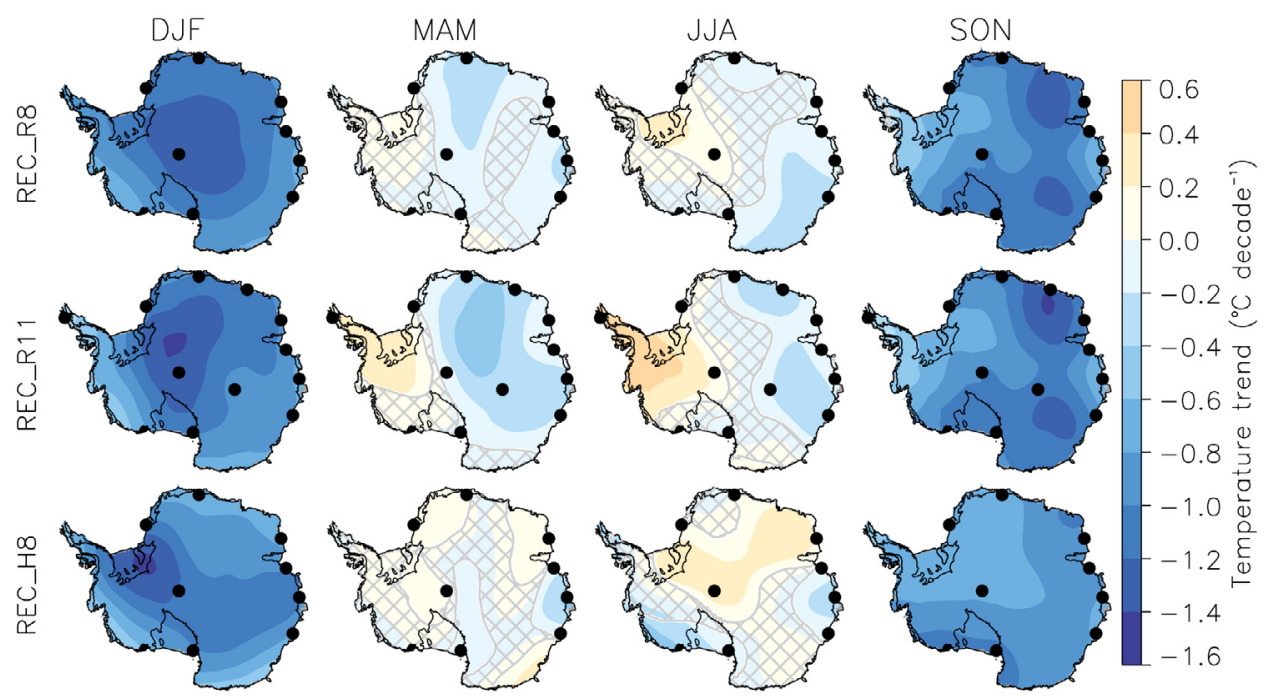

Figure 12. Same as Figure 10, but for reconstructed Antarctic $150 \mathrm{hPa}$ temperature trends. 


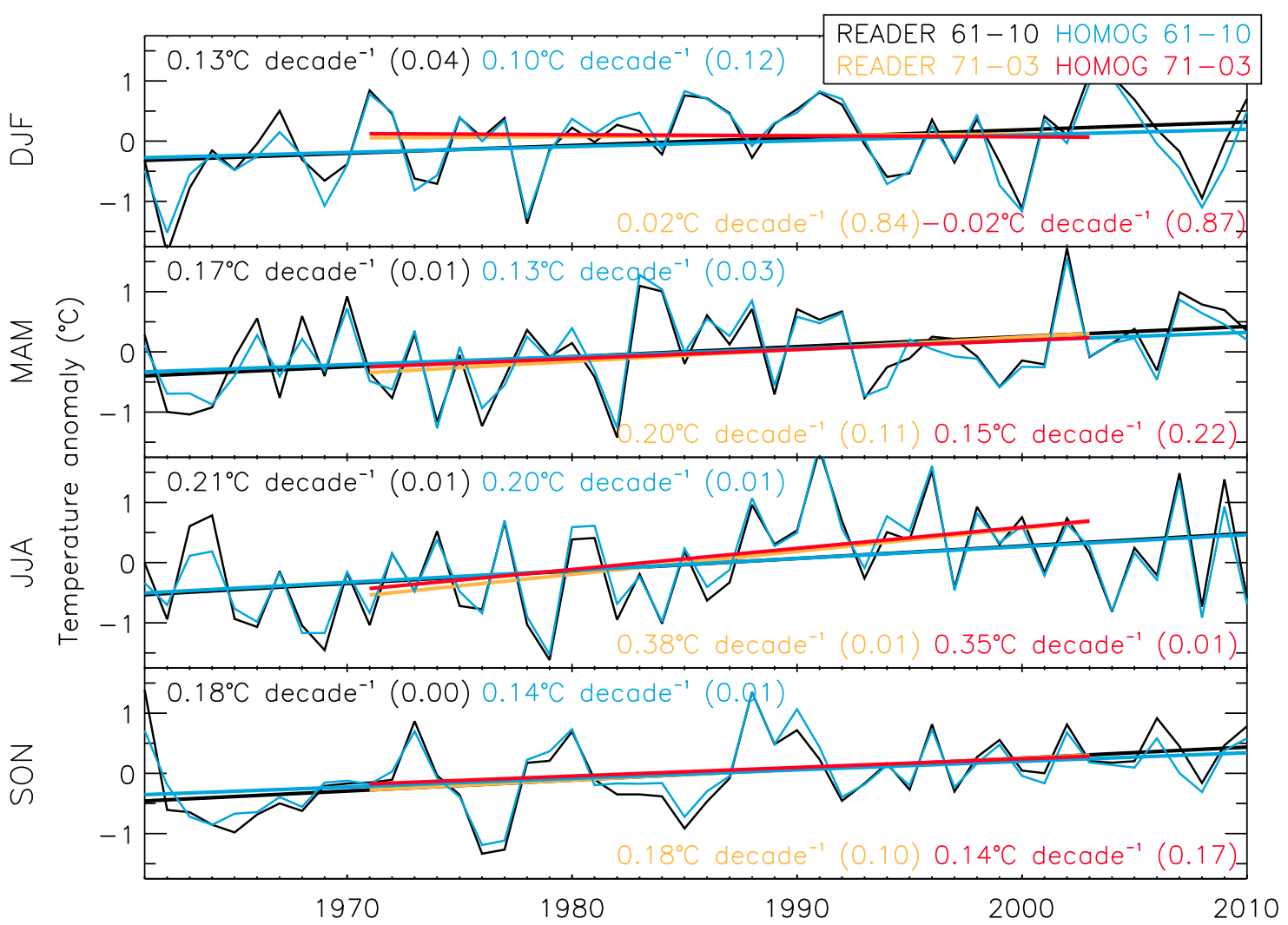

Figure 13. Multistation-mean $500 \mathrm{hPa}$ temperature time series for (top to bottom) the four seasons, and for both READER (black) and HOMOG (blue). Also shown are the linear trends over two time periods, 1961-2010 and 1971-2003. The colored numbers provide the regression slopes and their statistical significance ( $p$; in parentheses).

agreement between the spatial patterns of spring and summer cooling in all three reconstructions. The summer cooling is roughly centered over the pole, whereas in spring the maximum cooling is offset into the eastern hemisphere (with an extension over the Ross Ice shelf and surrounding coastal regions). In autumn and winter, the temperature changes are modest and often smaller than the model error. They are also more regionally variable and display greater inconsistencies between the reconstructions. Recall that a number of stations had significant differences in the sign of the observed trends at $150 \mathrm{hPa}$ in autumn and winter (Figure 5). Given these large uncertainties at the stations, we have little confidence in the spatial patterns shown by any of the $150 \mathrm{hPa}$ reconstructions for autumn and winter. However, one feature that is apparent in all three winter reconstructions is warming $\left(0.2-0.6^{\circ} \mathrm{C}\right.$ decade $^{-1}$; consistently larger than the model errors) over the Ronne Ice shelf and/or Ellsworth Land. This feature is also apparent during autumn in REC_R11, but not in either REC_R8 nor REC_H8.

[59] Figures $\mathrm{S} 9$ and $\mathrm{S} 10$ in the auxiliary material present equivalent $150 \mathrm{hPa}$ trend reconstructions but based on statistical models derived from the ERA-I and CFSR reanalyses, respectively. The reconstructions based on all three reanalyses are highly consistent and the main features identified above are present in all of them. The minor differences that exist are in the regional detail and not in the large-scale patterns.
[60] The strong seasonality of the $150 \mathrm{hPa}$ reconstructed trends is again clear from the area-weighted Antarctic-means in Figure 11. In spring and summer, the cooling rates vary between -0.8 and $-1.1^{\circ} \mathrm{C}$ decade $^{-1}$ in the different reconstructions. REC_R8 consistently shows the largest cooling and REC_H8 the smallest (but still large) cooling rates in these two seasons. Again this is consistent with differences in the multistation means between READER and HOMOG (Figure 6). The CFSR-based reconstructions show the strongest spring and summer cooling and the MERRA-based reconstructions show, in general, the weakest cooling in these seasons (Figure 11). However, these differences between the reconstructions using different reanalyses are small compared to the magnitudes of the reconstructed trends. In autumn and winter the reconstructions all show trends with small magnitudes (under $0.15^{\circ} \mathrm{C}$ decade $^{-1}$ ) compared to spring and summer. The READER-based reconstructions show Antarctic-mean cooling in autumn and winter, but REC_H8 (and the MERRAbased REC_R11 in winter) shows Antarctic-mean warming. The uncertainty in the sign of the Antarctic-mean change mirrors similar uncertainties in the sign of the $150 \mathrm{hPa}$ trends at many of the individual stations.

\section{Discussion}

[61] Turner et al. [2006] first identified mid-tropospheric warming in winter based on the 1971-2003 period. In comparison to that study, we find a slower winter warming 
rate at $500 \mathrm{hPa}$. In large part, the winter trend difference appears to be related to the differing time periods considered by the studies. Figure 13 shows the multistation mean observed $500 \mathrm{hPa}$ seasonal temperature time series from READER and HOMOG. Also shown are the linear trends over two periods: 1971-2003 as used by Turner et al. [2006] and $1961-2010$ as used in this study. The addition of ten years of temperature data at the start of the record (19611970 ) and seven extra years at the end of the record (2004 2010 ) reduces the winter warming rate by $40 \%$. In contrast, the summer warming rate is more than $0.1{ }^{\circ} \mathrm{C}$ decade $^{-1}$ greater over the longer period and becomes statistically significant in READER. Over the shorter period, winter is the only season when the trend is significant. Although the spring warming rate is unaffected and the autumn rate decreases slightly, both also achieve statistical significance over the longer period. Over the last half-century, both observations and our pan-Antarctic reconstructions suggest that the mid-tropospheric warming is not solely a winter phenomenon and is occurring in all seasons.

[62] Surface temperature trends over the last few decades have been linked to changes in atmospheric circulation, most notably a shift toward the positive phase of the Southern Annular Mode (SAM) [e.g., Thompson and Solomon, 2002; Kwok and Comiso, 2002; Gillett et al., 2006; Marshall, 2007]. However, the SAM trend cannot explain the tropospheric warming. The positive phase of the SAM is associated with negative temperature anomalies over most of Antarctica (excluding the Peninsula) and through the full depth of the atmosphere, because of anomalous divergence, rising air and the resultant adiabatic cooling [Thompson and Wallace, 2000; Sen Gupta and England, 2006]. In isolation, the SAM trend would have been expected to induce tropospheric cooling (auxiliary material Figure S11). To quantify this influence, we regressed Antarctic- and seasonal-mean $500 \mathrm{hPa}$ temperatures from MERRA against an observationally derived SAM index [see Marshall, 2003] for the reanalysis period 1979-2010. The resulting regression coefficients were multiplied by the seasonal trends in the SAM index over the full 50-year period, 1961-2010. We estimate that the SAM trends have led to cooling of -0.11 , $-0.12,-0.07$ and $-0.03^{\circ} \mathrm{C}$ decade $^{-1}$ at $500 \mathrm{hPa}$ over the last half-century, for summer, autumn, winter and spring, respectively (Figure S11). This not only indicates that changes in the SAM cannot explain the observed warming, but also that the SAM-related cooling has partially offset the mid-tropospheric warming. Furthermore, this has implications for future tropospheric temperature change. The SAM trend is projected to decrease, or even reverse in austral summer, over the coming decades in response to stratospheric ozone recovery [Son et al., 2008; Perlwitz et al., 2008; Arblaster et al., 2011]. If this scenario is realized, then future mid-tropospheric warming may be greater than observed over the last half-century.

[63] Our winter and particularly spring $500 \mathrm{hPa}$ reconstructions show a similar spatial pattern of temperature change to surface-based reconstructions since the late 1950s [Chapman and Walsh, 2007; Monaghan et al., 2008; Steig et al., 2009; O'Donnell et al., 2011] and observations post1979 [e.g., Ding et al., 2011; Schneider et al., 2012]. This suggests that the multidecadal surface and upper-air temperature trends may be coupled and thus, that the same mechanisms may be contributing to both. The winter and springtime surface warming over West Antarctica have recently been causally linked to tropical Pacific Ocean warming and associated teleconnections [Ding et al., 2011; Schneider et al., 2012]. The basic mechanism proposed is that tropical ocean warming has enhanced convection and led to a Rossby wave train response that influences atmospheric circulation over the Amundsen-Bellingshausen Sea. These circulation changes are proposed to have induced increased advection of warm air to West Antarctica. Although the aforementioned studies were concerned with the surface temperature changes, it is certainly plausible (perhaps even likely) that such tropospheric circulation changes could have driven warming aloft as well as at the surface. However, further work is required to confirm or disprove this hypothesis.

[64] Another potential cause of tropospheric warming in the cold seasons is increases in polar stratospheric clouds, which are proposed to have become more frequent as the stratosphere has cooled. By imposing idealized increases in polar stratospheric clouds in an atmospheric model, Lachlan-Cope et al. [2009] were able to simulate tropospheric warming over Antarctica in winter. This warming was associated with increases in downward long-wave radiation, most of which is absorbed in, and therefore warms, the few kilometers below the cloud. However, this mechanism can only operate in the cold season when stratospheric temperatures are cold enough for these clouds to form. Furthermore, while a $3 \%$ decade $^{-1}$ increase in the wintertime occurrence of polar stratospheric clouds has been reported at Dumont d'Urville since 1989 [David et al., 2010], there remain insufficient observations (in space and time) to confirm or disprove the proposed trends in their abundance or depth [Lachlan-Cope et al., 2009; David et al., 2010].

[65] Last, another potential mechanism that we have yet to mention is increasing greenhouse gas concentrations, which are expected to warm the troposphere in all seasons. It may be that the mid-tropospheric warming over the last halfcentury is the signal of anthropogenic greenhouse warming in Antarctica. The detection and attribution study of Gillett et al. [2008] found evidence of human-induced warming in Antarctica; however, that study only considered surface temperature change.

[66] Turning to the stratospheric cooling, this phenomena is understood to be closely associated with ozone depletion, with a smaller role played by increasing greenhouse gases and stratospheric water vapor [Randel and $W u, 1999$; Ramaswamy et al., 2001; Shine et al., 2003; Randel et al., 2009]. The seasonality of the observed stratospheric temperature changes - predominantly in spring and summer strongly point to the influence of ozone depletion [e.g., Randel and $W u, 1999]$. As the ozone hole recovers in the coming decades, the stratospheric cooling may weaken, although increasing greenhouse gas concentrations are also expected to continue to have a cooling influence in the polar stratosphere.

\section{Synthesis and Conclusions}

[67] We have presented a comprehensive analysis of observed multidecadal Antarctic temperature trends from the 
surface to the stratosphere, and the first spatial reconstructions of pan-Antarctic upper-air temperature change. Our analyses reveal significant temperatures changes aloft over the past half-century, with large-scale mid-tropospheric warming and stratospheric cooling. Statistically significant mid-tropospheric warming is found in all seasons, indicating that it is not solely the winter phenomenon first uncovered by Turner et al. [2006]. Stratospheric cooling has occurred predominantly in austral spring and summer.

[68] The spatial reconstructions strongly suggest that the year-round mid-tropospheric warming and the spring and summer stratospheric cooling extend across most of Antarctica, but with regionally varying magnitudes. In winter and spring, the mid-tropospheric warming is most pronounced over West Antarctica and the Ross Ice shelf and appears to be coupled to surface warming in these regions shown by other studies. We speculate that the winter and spring mid-tropospheric warming, like that at the surface, may in part be driven by tropical ocean warming and associated teleconnections. The stratospheric cooling is entirely consistent with the temperature response to ozone depletion.

[69] Acknowledgments. This work would not have been possible without the extensive data collation and quality-control undertaken by the SCAR READER project, and meteorological data provided by the international Antarctic science programs. We also thank the following institutes/ individuals for providing web access to data sets: British Antarctic Survey, NASA, NCEP, ECWMF, UKMO Hadley Centre, University of Vienna, Steve Sherwood and Gareth Marshall. Parts of this research were funded by the Australian Antarctic Science Advisory Committee and the Australian Research Council. We thank three anonymous reviewers for their insightful comments which significantly improved the manuscript.

\section{References}

Arblaster, J. M., G. A. Meehl, and D. J. Karoly (2011), Future climate change in the Southern Hemisphere: Competing effects of ozone and greenhouse gases, Geophys. Res. Lett., 38, L02701, doi:10.1029/ 2010 GL045384.

Bracegirdle, T. J., and G. J. Marshall (2012), The reliability of Antarctic tropospheric pressure and temperature in the latest global reanalyses, J. Clim., doi:10.1175/JCLI-D-11-00685.1, in press.

Bretherton, C. S., M. Widmann, V. P. Dymnikov, J. M. Wallace, and I. Bladé (1999), The effective number of spatial degrees of freedom of a timevarying field, J. Clim., 12, 1990-2009.

Bromwich, D. H., J. P. Nicolas, and A. J. Monaghan (2011), An assessment of precipitation changes over Antarctica and the Southern Ocean since 1989 in contemporary global reanalyses, J. Clim., 24, 4189-4209, doi:10.1175/2011JCLI4074.1.

Chapman, W. L., and J. E. Walsh (2007), A synthesis of Antarctic temperatures, J. Clim., 20, 4096-4117, doi:10.1175/JCLI4236.1.

Comiso, J. C. (2000), Variability and trends in Antarctic surface temperatures from in situ and satellite infrared measurements, J. Clim., 13, 1674-1696, doi:10.1175/1520-0442(2000)013<1674:VATIAS $>2.0$. $\mathrm{CO} ; 2$.

David, C., P. Keckhut, A. Armetta, J. Jumelet, M. Snels, M. Marchand, and S. Bekki (2010), Radiosonde stratospheric temperatures at Dumont d'Urville (Antarctica): Trends and link with polar stratospheric clouds, Atmos. Chem. Phys., 10, 3813-3825, doi:10.5194/acp-10-3813-2010.

Dee, D. P., et al. (2011), The ERA-Interim reanalysis: Configuration and performance of the data assimilation system, Q. J. R. Meteorol. Soc., 137, 553-597, doi:10.1002/qj.828.

Ding, Q., E. J. Steig, D. S. Battisti, and M. Kuttel (2011), Winter warming in West Antarctica caused by central tropical Pacific warming, Nat. Geosci., 4, 398-403, doi:10.1038/ngeo1129.

Doran, P. T., et al. (2002), Antarctic climate cooling and terrestrial ecosystem response, Nature, 415, 517-520, doi:10.1038/nature710.

Gillett, N. P., T. D. Kell, and P. D. Jones (2006), Regional climate impacts of the Southern Annular Mode, Geophys. Res. Lett., 33, L23704, doi:10.1029/2006GL027721.

Gillett, N. P., D. A. Stone, P. A. Stott, T. Nozawa, A. Y. Karpechko, G. C. Hergerl, M. F. Wehner, and P. D. Jones (2008), Attribution of polar warming to human influence, Nat. Geosci., 1, 750-754, doi:10.1038/ ngeo338.

Haimberger, L. (2007), Homogenization of radiosonde temperature time series using innovation statistics, J. Clim., 20, 1377-1403, doi:10.1175/ JCLI4050.1.

Haimberger, L., C. Travolato, and S. Sperka (2008), Towards elimination of the warm bias in historic radiosonde temperature records-Some new results from a comprehensive intercomparison of upper air data, J. Clim., 21, 4587-4606, doi:10.1175/2008JCLI1929.1.

Haimberger, L., C. Travolato, and S. Sperka (2012), Homogenization of the global radiosonde dataset through combined comparison with reanalysis background series and neighboring stations, J. Clim., doi:10.1175/JCLID-11-00668.1, in press.

Johanson, C. M., and Q. Fu (2007), Antarctic atmospheric temperature trend patterns from satellite observations, Geophys. Res. Lett., 34, L12703, doi:10.1029/2006GL029108.

Kalnay, E., et al. (1996), The NCEP-NCAR reanalysis product, Bull. Am. Meteorol. Soc., 77, 437-471, doi:10.1175/1520-0477(1996)077<0437: TNYRP $>2.0 . \mathrm{CO} ; 2$.

Kwok, R., and J. C. Comiso (2002), Spatial patterns of variability in Antarctic surface temperature: Connections to the Southern Hemisphere Annular Mode and the Southern Oscillation, Geophys. Res. Lett., 29(14), 1705, doi:10.1029/2002GL015415.

Lachlan-Cope, T. A., W. M. Connolley, J. Turner, H. Roscoe, G. J. Marshall, S. R. Colwell, M. Hopfner, and W. Ingram (2009), Antarctic winter tropospheric warming-The potential role of polar stratospheric clouds, a sensitivity study, Atmos. Sci. Lett., 10, 262-266.

Marshall, G. J. (2002), Trends in Antarctic geopotential height and temperature: A comparison between radiosonde and NCEP-NCAR reanalysis data, J. Clim., 15, 659-674, doi:10.1175/1520-0442(2002)015<0659: TIAGHA $>2.0 . \mathrm{CO} ; 2$.

Marshall, G. J. (2003), Trends in the Southern Annular Mode from observations and reanalyses, J. Clim., 16, 4134-4143, doi:10.1175/1520-0442 (2003) $016<4134$ :TITSAM $>2.0$. CO;2.

Marshall, G. J. (2007), Half-century seasonal relationships between the Southern Annular Mode and Antarctic temperatures, Int. J. Climatol., 27, 373-383, doi:10.1002/joc.1407.

Marshall, G. J., A. Orr, N. P. M. Van Lipzig, and J. C. King (2006), The impact of changing Southern Hemisphere Annular Mode on Antarctic Peninsula summer temperatures, J. Clim., 19, 5388-5404, doi:10.1175/ JCLI3844.1.

McCarthy, M. P. (2008), Spatial sampling requirements for monitoring upper-air climate change with radiosondes, Int. J. Climatol., 28, 985993, doi:10.1002/joc.1611.

Monaghan, A. J., D. H. Bromwich, W. Chapman, and J. C. Comiso (2008), Recent variability and trends of Antarctic near-surface temperature, J. Geophys. Res., 113, D04105, doi:10.1029/2007JD009094.

Muto, A., T. A. Scambos, K. Steffen, A. G. Slater, and G. D. Clow (2011), Recent surface temperature trends in the interior of East Antarctica from borehole firn temperature measurements and geophysical inverse methods, Geophys. Res. Lett., 38, L15502, doi:10.1029/2011GL048086.

Neff, W., J. Perlwitz, and M. Hoerling (2008), Observational evidence for asymmetric changes in tropospheric heights over Antarctica on decadal time scales, Geophys. Res. Lett., 35, L18703, doi:10.1029/2008GL035074.

O'Donnell, R., N. Lewis, S. McIntyre, and J. Condon (2011), Improved methods for PCA-based reconstructions: Case study using the Steig et al. (2009) Antarctic temperature reconstruction, J. Clim., 24, 20992115, doi:10.1175/2010JCLI3656.1.

Perlwitz, J., S. Pawson, R. L. Fogt, J. E. Nielsen, and W. D. Neff (2008), Impact of stratospheric ozone hole recovery on Antarctic climate, Geophys. Res. Lett., 35, L08714, doi:10.1029/2008GL033317.

Ramaswamy, V., et al. (2001), Stratospheric temperature trends: Observations and model simulations, Rev. Geophys., 39, 71-122, doi:10.1029/ 1999RG000065.

Randel, W. J., and F. Wu (1999), Cooling of the Arctic and Antarctic polar stratospheres due to ozone depletion, J. Clim., 12, 1467-1479, doi:10.1175/1520-0442(1999)012<1467:COTAAA > 2.0.CO;2.

Randel, W. J., et al. (2009), An update of observed stratospheric temperature trends, J. Geophys. Res., 114, D02107, doi:10.1029/2008JD010421.

Rienecker, M. M., et al. (2011), MERRA: NASA's Modern-Era Retrospective Analysis for Research and Applications, J. Clim., 24, 3624-3648, doi:10.1175/JCLI-D-11-00015.1.

Saha, S., et al. (2010), The NCEP Climate Forecast System Reanalysis, Bull. Am. Meteorol. Soc., 91, 1015-1057, doi:10.1175/2010BAMS3001.1.

Schneider, D. P., C. Deser, and Y. M. Okumura (2012), An assessment and interpretation of the observed warming of West Antarctica in the austral spring, Clim. Dyn., 38, 323-347, doi:10.1007/s00382-010-0985-x. 
Sen Gupta, A., and M. H. England (2006), Coupled ocean-atmosphere-ice response to variations in the Southern Annular Mode, J. Clim., 19, 4457-4486, doi:10.1175/JCLI3843.1.

Sherwood, S. C. (2007), Simultaneous detection of climate change and observing biases in a network with incomplete sampling, J. Clim., 20, 4047-4062, doi:10.1175/JCLI4215.1.

Sherwood, S. C., C. L. Meyer, R. J. Allen, and H. A. Titchner (2008), Robust tropospheric warming revealed by iteratively homogenized radiosonde data, J. Clim., 21, 5336-5352, doi:10.1175/2008JCLI2320.1.

Shine, K. P., et al. (2003), A comparison of model-simulated trends in stratospheric temperatures, Q. J. R. Meteorol. Soc., 129, 1565-1588, doi:10.1256/qj.02.186.

Son, S., L. Polvani, D. Waugh, H. Akiyoshi, R. Garcia, D. Kinnison, S. Pawson, E. Razonov, T. Shepherd, and K. Shibata (2008), The impact of stratospheric ozone recovery on the Southern Hemisphere westerly jet, Science, 320, 1486-1489, doi:10.1126/science.1155939.

Steig, E. J., D. P. Schneider, S. D. Rutherford, M. E. Mann, J. C. Comiso, and D. T. Shindell (2009), Warming of the Antarctic ice-sheet since the 1957 International Geophysical Year, Nature, 457, 459-462, doi: $10.1038 /$ nature07669.

Thompson, D. W. J., and S. Solomon (2002), Interpretation of recent Southern Hemisphere climate change, Science, 296, 895-899, doi:10.1126/ science. 1069270 .

Thompson, D. W. J., and J. M. Wallace (2000), Annular modes in the extratropical circulation. Part I: Month-to-month variability, J. Clim., 13, 1000-1016, doi:10.1175/1520-0442(2000)013<1000:AMITEC $>2.0$.CO;2.
Thorne, P. W., et al. (2005), Revisiting radiosonde upper air temperatures from 1958 to 2002, J. Geophys. Res., 110, D18105, doi:10.1029/ 2004JD005753.

Thorne, P. W., et al. (2011), Tropospheric temperature trends: History on an ongoing controversy, Wiley Interdiscip. Rev. Clim. Change, 2, 66-88, doi:10.1002/wcc. 80 .

Titchner, H. A., P. W. Thorne, M. P. McCarthy, S. F. B. Tett, L. Haimberger, and D. E. Parker (2009), Critically reassessing tropospheric temperature trends from radiosondes using realistic validation experiments, J. Clim., 22, 465-485, doi:10.1175/2008JCLI2419.1.

Turner, J., and J. Overland (2009), Contrasting climate change in the two polar regions, Polar Res., 28, 146-164, doi:10.1111/j.1751-8369.2009.00128.x.

Turner, J., S. R. Colwell, G. J. Marshall, T. A. Lachlan-Cope, A. M. Carleton, P. D. Jones, V. Lagun, P. A. Reid, and S. Iagovkina (2004), The SCAR READER project: Towards a high-quality database of mean Antarctic meteorological observations, J. Clim., 17, 2890-2898, doi:10.1175/1520-0442 (2004)017<2890:TSRPTA $>2.0$. CO; 2 .

Turner, J., S. R. Colwell, G. J. Marshall, T. A. Lachlan-Cope, A. M. Carleton, P. D. Jones, V. Lagun, P. A. Reid, and S. Iagovkina (2005), Antarctic climate change during the last 50 years, Int. J. Climatol., 25, 279-294, doi:10.1002/joc.1130.

Turner, J., T. A. Lachlan-Cope, S. Colwell, G. J. Marshall, and W. M. Connolley (2006), Significant warming of the Antarctic winter troposphere, Science, 311, 1914-1917, doi:10.1126/science.1121652. 